\section{RESEARCH ARTICLE \\ 10.1029/2019JB018883 \\ Effect of Fluid Viscosity on Fault Reactivation and Coseismic Weakening}

Special Section:

Physical Properties of Rocks, Friction and Fracturing: The

Walsh Volume

Key Points:

- The viscosity of the injected fluid does not influence the initial strength of experimental faults

- Fault weakening mechanisms during simulated seismic slip depend on fluid viscosity

- The magnitude of the breakdown energy is independent of the fault weakening mechanism

Supporting Information:

- Supporting Information S1

Correspondence to:

C. Cornelio,

chiara.cornelio@epfl.ch

Citation:

Cornelio, C., Passelègue, F. X., Spagnuolo, E., Di Toro, G., \& Violay, M. (2020). Effect of fluid viscosity on fault reactivation and coseismic weakening. Journal of Geophysical Research: Solid Earth, 125, e2019JB018883. https://doi. org/10.1029/2019JB018883

Received 11 OCT 2019 Accepted 25 DEC 2019

Accepted article online 30 DEC 2019

(C)2019. American Geophysical Union. All Rights Reserved.

\author{
C. Cornelio $^{1}$, F. X. Passelègue ${ }^{1}$, E. Spagnuolo ${ }^{2}$, G. Di Toro ${ }^{2,3}$, and M. Violay ${ }^{1}$ \\ ${ }^{1}$ Laboratory of Experimental Rock Mechanics, EPFL, Lausanne, Switzerland, ${ }^{2}$ Istituto Nazionale di Geofisica e \\ Vulcanologia, Rome, Italy, ${ }^{3}$ Dipartimento di Geoscienze, Università degli Studi di Padova, Padua, Italy
}

\begin{abstract}
High-viscosity fluids are often used during hydraulic fracking operations in georeservoirs. Here we performed dedicated experiments to study the influence of fluid viscosity on fault reactivation and associated induced earthquakes. Experiments were conducted in the rotary-shear machine Slow to HIgh Velocity Apparatus on experimental fault of Westerly granite saturated by fluids with increasing viscosity (at room temperature) from $0.1 \mathrm{mPa} \mathrm{s}$ (water) to $1.2 \mathrm{~Pa} \mathrm{~s}$ (99\% glycerol). Fault reactivation was triggered at constant effective normal stress by increasing the shear stress acting on the fault. Our results showed that independent of the viscosity, fault reactivation followed a Coulomb-failure criterion. Instead, fluid viscosity affected the fault weakening mechanism: flash heating was the dominant weakening mechanism in room humidity and water-saturated conditions, whereas the presence of more viscous fluids favored the activation of elasto-hydrodynamic lubrication. Independent of the weakening mechanism, the breakdown work $W_{\mathrm{b}}$ dissipated during seismic faulting increased with slip $U$ following a power law $\left(W_{\mathrm{b}} \propto U^{1.25}\right)$ in agreement with seismological estimates of natural and induced earthquakes.

Plain Language Summary One of the most alarming recent findings in solid earth sciences is the worldwide exponential increase of human-induced seismicity. This is due to engineering operations in deep reservoirs for hydrocarbon production, $\mathrm{CO}_{2}$ storage, wastewater storage, and exploitation of geothermal resources which result in the reactivation of faults hosted in the reservoirs. While the reactivation of faults due to fluid pressure has been extensively studied, the influence of fluid properties including its viscosity has been overlooked, even if the viscosity of injected fluids spans from the one of water to that of honey. In this study, we discuss the influence of stress perturbations on the reactivation of fluid-permeated experimental faults and on induced earthquakes. Our experimental observations suggest that the viscosity of the fluid does not influence the onset of fault reactivation. Instead, the viscosity of the fluid controls the type of deformation mechanism activated during induced earthquake rupture.
\end{abstract}

\section{Introduction}

Earthquakes rupture nucleating and propagating along faults result from the frictional response of fault materials to local or far-field ambient stress variations. In nature, stress can increase slowly due to tectonic loading up to the critical strength of faults, or change suddenly due to (1) earthquake ruptures propagating in the vicinity of the fault or (2) fluid migration (Gomberg et al., 1997; Harris, 1998; Kilb et al., 2000; Miller et al., 2004; Sibson, 1992). In georeservoirs, induced earthquakes triggered by pore pressure variations (i.e., effective stress variations) during engineering operations are a major issue for the future development of hydrocarbon production, geothermal resources, $\mathrm{CO}_{2}$, and nuclear waste storage (Cornet et al., 1997; Ellsworth, 2013; Guglielmi et al., 2015; Majer et al., 2007).

Faults respond to stress variations by either (1) remaining in a locked state or (2) slipping stably at low slip rates $(\ll 1 \mathrm{~mm} / \mathrm{s})$ or $(3)$ accelerating toward seismic slip rates $(\gg 1 \mathrm{~mm} / \mathrm{s}$, unstable regime), depending on the initial stress conditions and wall rock stiffness (Scholz, 2019). The frictionally stable and unstable regimes ( $\mathrm{Gu}$ et al., 1984) can be described in the framework of the rate-and-state friction law (Dieterich, 1979; Rice \& Ruina, 1983) where the frictional response of a fault varies with the previous loading history, and depends on both the instantaneous slip-rate $V$ and a state variable accounting for the evolution with time of the sliding interface. 

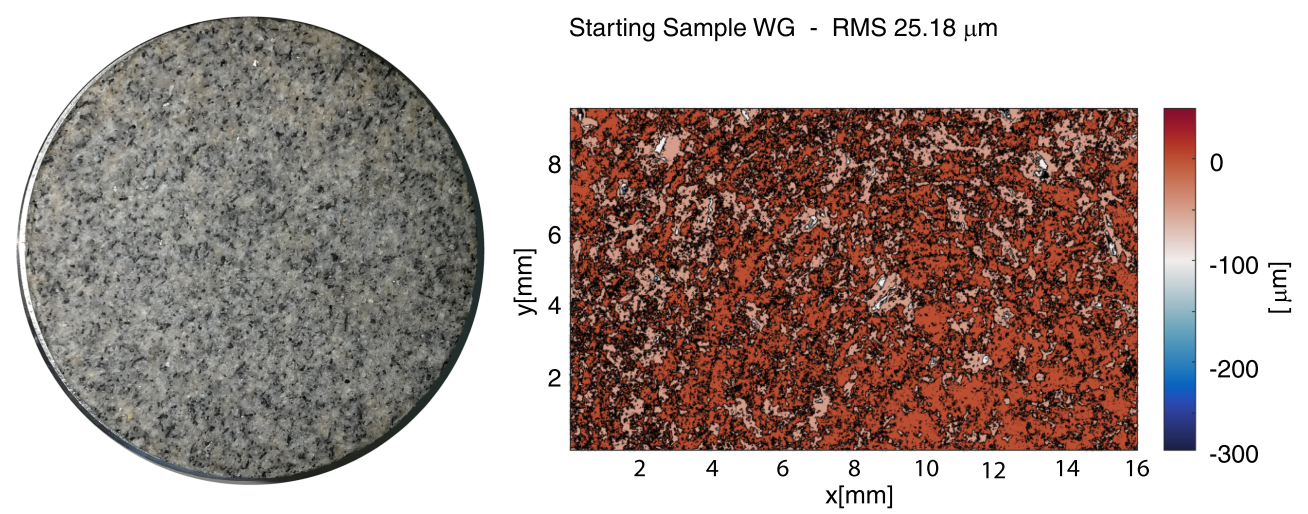

Figure 1. Initial surface and roughness of the Westerly granite samples. (a) Photo of the initial $50 \mathrm{~mm}$ in diameter sample of Westerly granite. (b) The RMS surface roughness obtained using the optical profilometer.

To understand the effect of the fluid pressure on the rate-and-state friction law variables, velocity controlled experiments under pore fluid conditions have been conducted (Ikari et al., 2009; Niemeijer \& Collettini, 2014; Scuderi \& Collettini, 2016). However, controlling the shear stress and the pore pressure (the pressure of the fluid in saturated and drained condition) up to the onset of slip events rather than controlling the slip rate and measuring the shear strength evolution is more representative to reservoir engineering and natural conditions, where stress variations and frictional properties of the fault materials control the mechanical response of the fault zone (Cornet, 2016; Goertz-Allmann et al., 2011; Wu et al., 2018; Zoback \& Harjes, 1997). A first step in this direction was recently achieved by studying the effect of pore fluid variations on experimental fault reactivation (Giacomel et al., 2018; Passelègue et al., 2018; Scuderi et al., 2017; Ye \& Ghassemi, 2018). However, the composition of the fluid used in these studies was limited to pure water or water and carbon dioxide mixtures and the role of fluid viscosity was neglected.

In geoengineering practice, the viscosity of the injected fluids varies over 4 orders in magnitude, from $1 \mathrm{mPa}$ $\mathrm{s}$ for liquid water to $10 \mathrm{~Pa}$ s for fracturing fluids (Economides \& Boney, 2000), and recent experimental studies showed that fluid viscosity controls seismic source parameters, including stress drops, the weakening distance, and the earthquake energy budget (Cornelio et al., 2019). Here, we discuss the role of fluid viscosity on both the onset of fault reactivation and the associated slip events by exploiting a novel experimental technique. This consists of loading an experimental fault under realistic geoengineering effective stress and environmental conditions (Giacomel et al., 2018), which span from room humidity to high-viscosity fluid pressurized conditions.

\section{Materials and Methods}

We conducted seven shear-stress controlled experiments on the rotary shear apparatus named SHIVA (Slow to HIgh Velocity Apparatus; see Di Toro et al. (2010) and Niemeijer et al. (2011) for details on the machine and the acquisition system). Experiments were performed on 50-mm-diameter full cylinders of Westerly granite, selected as an analogous of the target lithology for geothermal reservoirs. Westerly granite is a homogeneous, isotropic, fine grain size $(<1 \mathrm{~mm})$, low porosity $(<2 \%$ measured using the triple-weighing method), and low permeability $\left(\sim 10^{-19} \mathrm{~m}^{2}\right)$ rock (Nasseri et al., 2009). The low porosity and permeability result in negligible fluid diffusion in the rock matrix during the experiments discussed here. The samples were prepared following the procedure described by Nielsen et al. (2012) to ensure sample alignment and parallelism of the opposite sliding surfaces once the cylinders were installed in the sample holders of SHIVA. Sliding surfaces were roughened by using $80 \mathrm{SiC}$ abrasive paper to produce small irregularities called asperities. The three-dimensional (3-D) surface roughness was measured as the quadratic mean (root mean square). The RMS was determined on $10 \times 16 \mathrm{~mm}$ rectangular area of the surface of the Westerly granite sample before the experiments (Figure 1) using an optical profilometer ContourGT-I 3D Optical Microscope, Bruker Nano surfaces Division. The scan of the surfaces was performed by stitching images of $20 \times 20 \mu \mathrm{m}^{2}$ with an overlap of $20 \%$ between two adjacent areas. The RMS of the fault surface of 
Table 1

Summary of the Experimental Conditions

\begin{tabular}{llllllll}
\hline Experiment & Condition & $\eta(\mathrm{mPa} \mathrm{s})$ & $\sigma_{n}(\mathrm{MPa})$ & $P_{f}(\mathrm{MPa})$ & $\sigma_{\text {eff }}(\mathrm{MPa})$ & $\tau_{\text {imp }}(\mathrm{MPa})$ & $\mu_{\text {peak }}$ \\
\hline s1409 & RH & & 9.847 & & 9.847 & 6.364 & 0.646 \\
s1487 & RH & & 9.741 & & 9.741 & 6.069 & 0.623 \\
s1407 & Water & 1.002 & 12.109 & 2.702 & 9.407 & 6.822 & 0.725 \\
s1488 & 60\% glyc & 10.8 & 11.861 & 2.641 & 9.220 & 7.321 & 0.794 \\
s1781 & 85\% glyc & 108.4 & 12.463 & 2.473 & 9.990 & 6.977 & 0.698 \\
s1596 & $99 \%$ glyc & 1226 & 11.902 & 2.738 & 9.164 & 6.968 & 0.760 \\
s1406 & $99 \%$ glyc & 1226 & 12.080 & 2.729 & 9.352 & 6.538 & 0.699 \\
\hline
\end{tabular}

Note. Shear stress at fault reactivation $=\tau_{\text {imp }}$. Condition: normal stress $\sigma_{n}$, fluid pressure $P_{f}$, effective normal stress $\sigma_{\text {eff }}$, and peak friction coefficient $\mu_{\text {peak. }}$

Westerly granite before sliding was around $\mathbf{R M S}=\mathbf{2 5 . 1 8} \boldsymbol{\mu \mathrm { m }}$ so we assumed an initial average asperity height of $\boldsymbol{w}_{\mathbf{0}}=\mathbf{2 5} \boldsymbol{\mu \mathrm { m }}$ (Figure 1).

Experiments were conducted at the same effective stress conditions $\sigma_{n}^{\prime}=\sigma_{n}-P_{f} \cong \mathbf{1 0} \mathbf{M P a}$, where a normal stress $\sigma_{\boldsymbol{n}}$ of $\sim 13 \mathrm{MPa}$ and a fluid pressure $\boldsymbol{P}_{\boldsymbol{f}}$ of $\sim 2.7 \mathrm{MPa}$ (pressure of the fluid in the slipping surface) were applied and maintained constant during the experiments (Table 1). To perform experiments in the presence of fluids, SHIVA was equipped with a pressurizing system which consisted of a fluid pressure vessel, a membrane pump (with a $30-\mathrm{cm}^{3}$ fluid capacity), a pressure multiplier that imposed up to $15 \mathrm{MPa}$ of fluid pressure, a pressure regulator, and valves and pipes (Violay et al., 2013, 2014, 2015). The tests were performed under drained conditions; that is, the vessel was connected to the fluid reservoir to keep the fluid pressure macroscopically constant during the entire experiment (Figure $2 \mathrm{~b}$ ). The procedure for experiments performed in presence of fluids consisted in (1) applying an initial axial stress $\sigma_{\mathrm{n}}=0.8 \mathrm{MPa}$, (2) increasing the fluid pressure by injecting fluids radially in the vessel up to $0.5 \mathrm{MPa}$, (3) increasing the axial stress $\sigma_{\mathrm{n}}$ up to the target value, and (4) increasing the fluid pressure up to the target value.
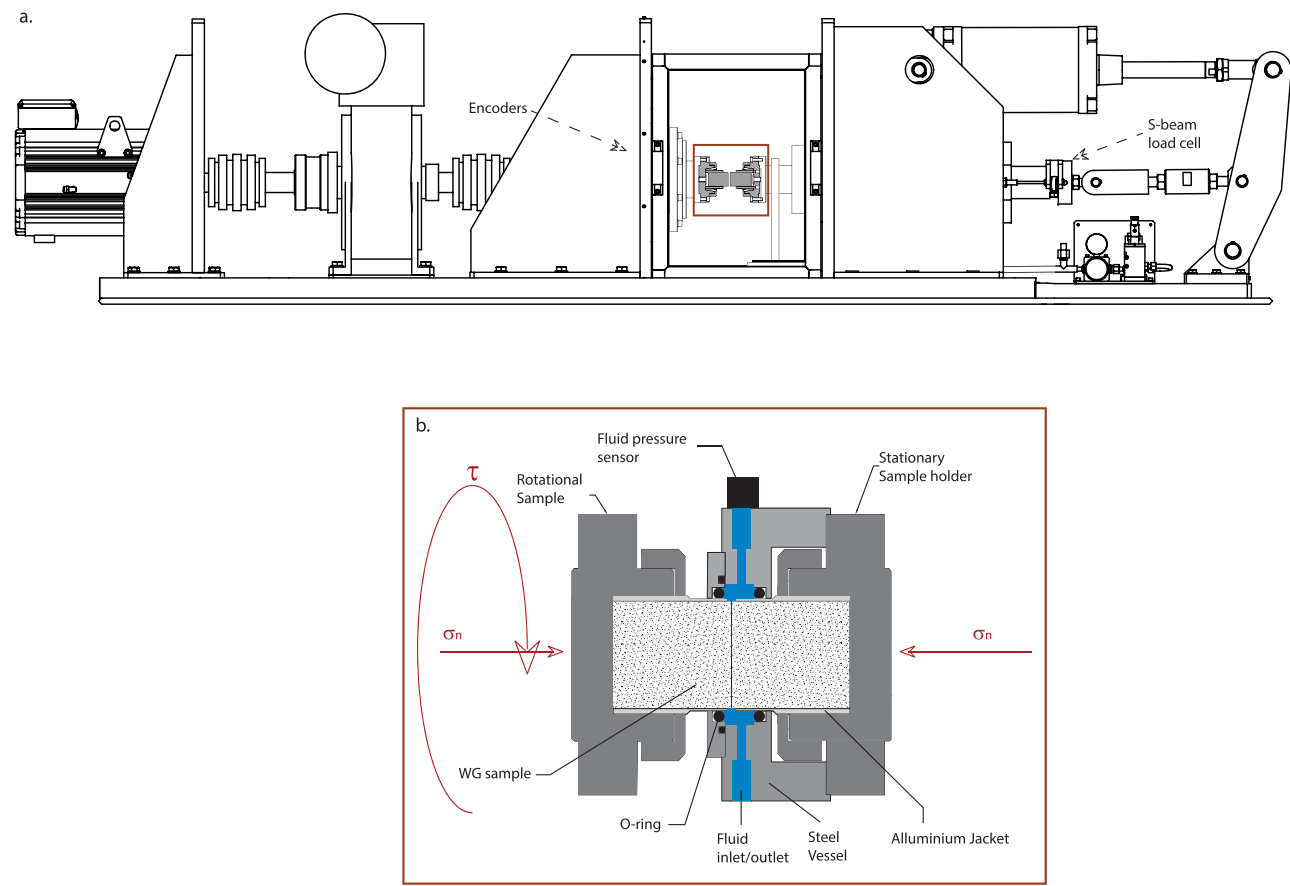

Figure 2. Experimental assembly. (a) Sketch of the apparatus SHIVA (modified from Passelègue et al., 2016). The approximate position of the encoders and the S-beam cell are reported and (b) zoom on the sample assembly and fluid pressure vessel. The fluid pressure is kept constant during the experiments thanks to the membrane pump that is directly connected to the pressure vessel. 
Once the target effective normal stress of $\sim 10 \mathrm{MPa}$ was achieved, the shear stress $\tau$ was gradually increased by controlling the torque with stepwise increments corresponding to $\sim 0.5 \mathrm{MPa}$ (resolution of $0.1 \mathrm{MPa}$ ) and a

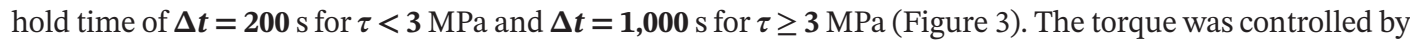
the engine via feedback control on the motor current with an update frequency of $16 \mathrm{kHz}$. The control system is an open loop control on the shear stress which is measured downstream of the slip surface via an independent measure on the S-beam load cell (Figure 2a). This independent measure ensures the achievement of spontaneous evolution of both shear strength and slip (and slip rate) of the experimental fault. Two encoders recorded the spontaneous evolution of the slip in response to the applied torque. The torque stepwise increase was applied up to the onset of a main frictional instability (see section $\mathbf{3}$ for full description) defined as the spontaneous acceleration of the fault slip rate up to a target velocity of $V_{\max }=0.2 \mathrm{~m} / \mathrm{s}$ (or $\mathrm{V}_{\text {max }}=0.2 \mathrm{~m} / \mathrm{s}$ for the experiment $\mathrm{s} 1781$; see supporting information). At this slip rate, the control system automatically switched from constant shear stress to constant slip-rate control maintaining $V_{\max }=0.1 \mathrm{~m} /$ $\mathrm{s}$ ( or $\mathrm{V}_{\max }=0.2 \mathrm{~m} / \mathrm{s}$ for experiment s1781) until either the spontaneous recovery of the imposed shear stress or the manual arrest of the experiment. Normal stress $\sigma_{\boldsymbol{n}}$, pore fluid pressure $P_{f}$, slip, slip-rate $V$, and shear stress $\tau$ were acquired at $125 \mathrm{~Hz}$ and determined using the procedure suggested in Niemeijer et al. (2011) and Tsutsumi and Shimamoto (1997). The elastic and inelastic slip and the slip rate were corrected for the stiffness of the apparatus $(\boldsymbol{k}=\mathbf{0 . 0 7} \mathbf{M P a} / \mu \mathbf{m}$; equation (1)):

$$
V_{\text {samp }}=V_{\text {meas }}-k^{-1} \frac{d \tau}{d t}
$$

The experimental conditions and the evolution of the shear stress and slip rate for all the explored conditions are reported in Table 1 and Figure 3, respectively.

Four different $\%$ weight $/ \%$ weight mixtures of distilled water and glycerol were used as pressurized fluids: $100 \%$ distilled water, $40 \%$ water $/ 60 \%$ glycerol, $15 \%$ water $/ 85 \%$ glycerol, and $99 \%$ glycerol (the remaining $1 \%$ being impurities). Viscosity values of $1.002 \mathrm{mPa} \mathrm{s}$ (distilled water), $10.9 \mathrm{mPa} \mathrm{s}$ (40\% water/60\% glycerol), $108.4 \mathrm{mPa}$ s (15\% water/85\% glycerol), and 1,226.0 mPa s (99\% glycerol) were measured using calibrated Ubbelohde capillary viscometers (Cannon Instrument Company) at a temperature of $20{ }^{\circ} \mathrm{C}$.

\section{Results}

The evolution of shear stress and slip rate during the experiments can be described by three stages (I, II, and III; Figure 4).

Stage I. Single slip pulses under shear stress-step loading. In all the experiments and independent of the presence and viscosity of fluids, from the beginning of the experiment (i.e., $\tau=0 \mathrm{MPa}$ ) to $\tau=2.5 \mathrm{MPa}$, the experimental fault remained locked (elastic loading) and no slip was measured. From $2.5<\tau<6 \mathrm{MPa}$, each increment of shear stress resulted in a single slip pulse with a total slip distance $\Delta U_{\text {tot }}<0.3 \mathrm{~mm}$ and maximum slip-rate $V \sim 10^{-5} \mathrm{~m} / \mathrm{s}$ (Figure $4 \mathrm{~b}$ ). These short-lived slip pulses did not induce any measurable drop in shear stress, suggesting that the experimental fault recovered quickly from the stress perturbation.

Stage II: Series of spontaneous slip bursts under shear stress-step loading. With increasing shear stress and independent of the presence and viscosity of the fluid, we observed spontaneous but isolated slip events with total slip distances between $0.3 \mathrm{~mm}<\Delta U_{\text {tot }}<0.25 \mathrm{~m}$ occurring at $V<0.1 \mathrm{~m} / \mathrm{s}$ (this was the maximum allowed spontaneous slip rate; see section 2). Differently to the slip pulses of stage I, these slip bursts were associated to shear stress drops of less than $10 \%$ of the imposed shear stress $\tau_{\text {imp }}$ (Figures $3,4 \mathrm{c}$, and $4 \mathrm{~d}$ ).

Stage III. Unstable slip behavior (achievement of a critical unstable frictional behavior): For $\tau>6 \mathrm{MPa}$, and in particular for an apparent friction coefficient $\mu=\frac{\tau}{\sigma_{n, e f f}}=0.71 \pm 0.07$ (Figure 5), the frictional macroscopic behavior of the fault became unstable, independent of the presence and viscosity of the fluids. The unstable frictional behavior initiated with the occurrence of tens of short-lived slip events with $\Delta U_{\text {tot }}<0.25$ $\mathrm{m}$ at $V \leq 0.1 \mathrm{~m} / \mathrm{s}$ ending with a long-lived slip event with $\Delta U_{t o t}>0.25 \mathrm{~m}$ at the maximum allowed $V=0.1$ $\mathrm{m} / \mathrm{s}$ (Figure $4 \mathrm{~d}$ ). The threshold slip rate of $0.1 \mathrm{~m} / \mathrm{s}$ was selected because large enough to allow for the frictional weakening of the fault and, approaching the slip rate, multiple slip events were induced in our experimental configuration as the fault is running in a marginally stable behavior (Spagnuolo et al., 2016). Each short-lived 
a.

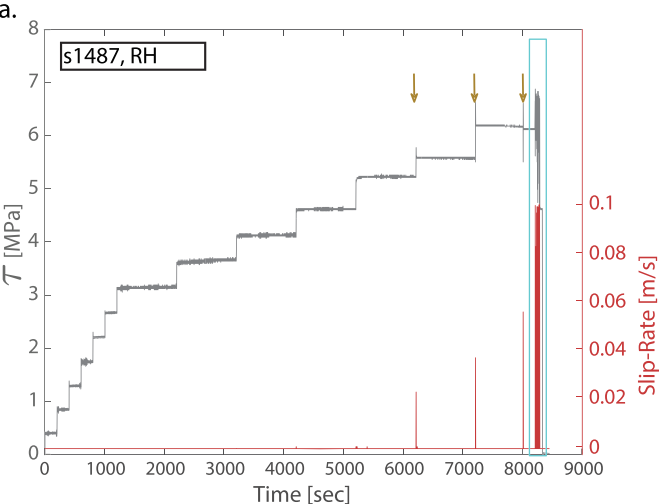

c.

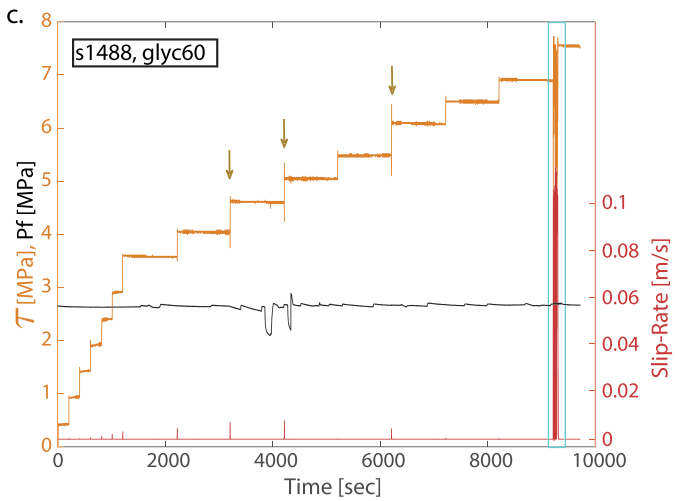

e.

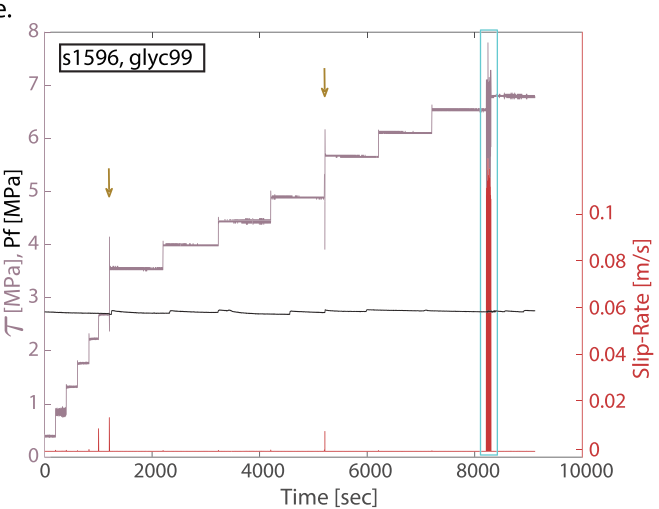

b.

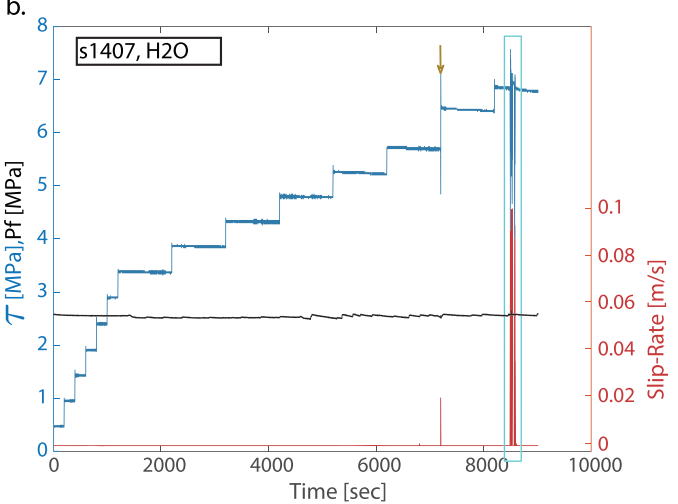

d.

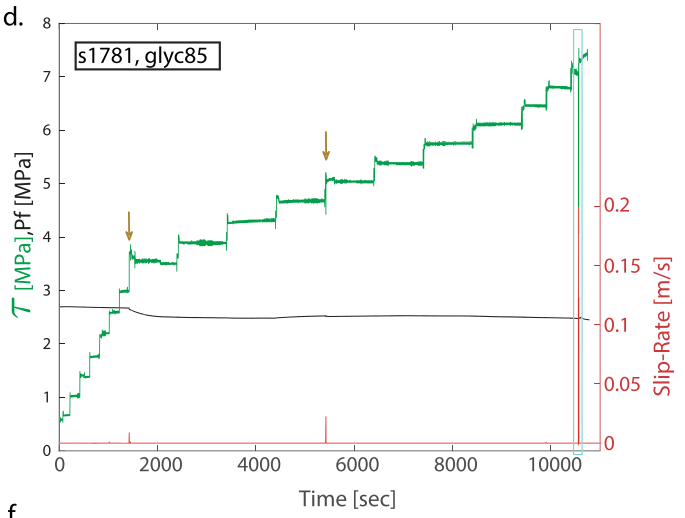

f.

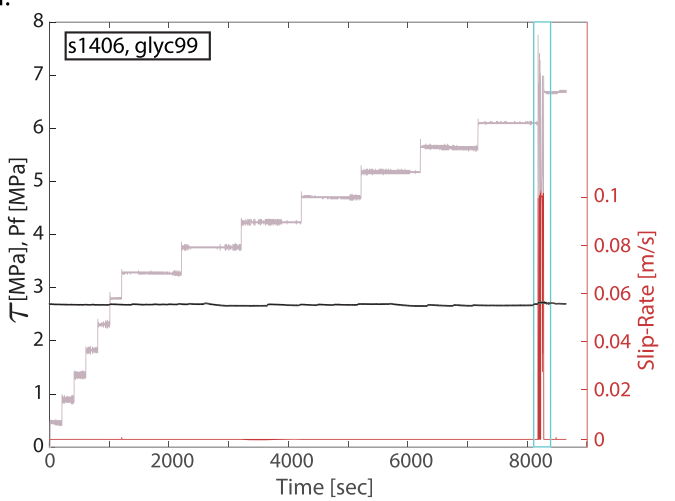

Figure 3. Recorded shear stress $\tau$ (measured at the S-beam load cell), fluid pressure Pf, and slip-rate V evolution versus time in the experiments (see main text for description). All the experiments were conducted at an effective normal stress of approximately $10 \mathrm{MPa}$. (a) Experiment s1487, room-humidity (RH) conditions. (b) Experiment s1407, distilled water (1 mPa s). (c) Experiment s1488, mixture of $40 \%$ water $/ 60 \%$ glycerol $(\eta=10.8 \mathrm{mPa}$ s). (d) Experiment s1781 = mixture of $15 \%$ water $/ 85 \%$ glycerol ( $\eta=109 \mathrm{mPa} \mathrm{s})$. (e) Experiment s1596, pure glycerol or $99 \%$ glycerol $(\eta=1,226 \mathrm{mPa}$ s). (f) Experiment s1406, pure glycerol or $99 \%$ glycerol $(\eta=1,226 \mathrm{mPa}$ s). The ocher-in-color arrows mark the slip bursts (see description of stage II in the main text) and the cyan rectangle the achievement of a critical unstable frictional behavior (see description of stage III in the main text).

slip event consisted in a shear stress drop $\Delta \tau$ (difference between the imposed shear stress $\tau_{\text {imp }}$ and the minimum value of the shear stress $\left.\tau_{\text {min }}\right)$ and in the spontaneous recovery to a peak shear stress $\left(\tau_{\text {peak }}\right)$ slightly higher than the imposed shear stress (see in Figures $4 \mathrm{~d}$ and 12a for a zoom on the first short-lived slip event of s1488). In the long-lived slip event at the maximum allowed $V=0.1 \mathrm{~m} / \mathrm{s}, U$ increased with increased fluid viscosity from $0.36 \mathrm{~m}$ for $100 \%$ distilled water to $0.72 \mathrm{~m}$ for $99 \%$ glycerol. The experiment was then manually stopped once the shear stress recovered (spontaneously) the $\tau_{\text {imp }}$ (Figure $4 \mathrm{~d}$ ).

To understand the influence of fluid viscosity on the fault weakening mechanism active during stage III (especially during the last long-lived slip event), we analyzed the evolution of the apparent friction 


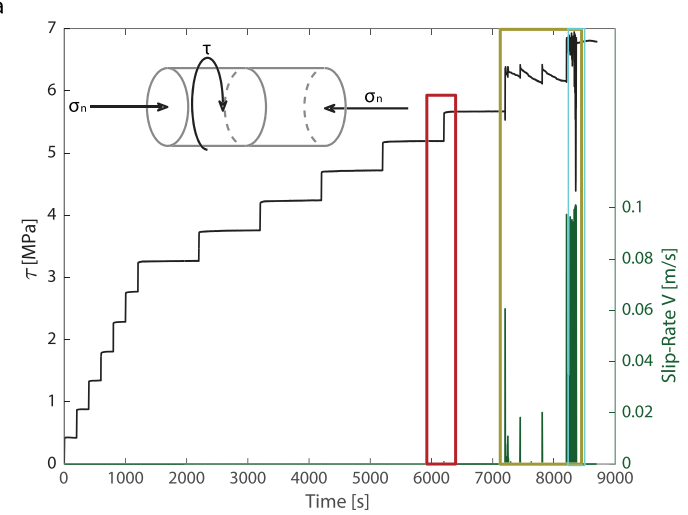

b Stage I- slip pulse $\times 10^{-5}$

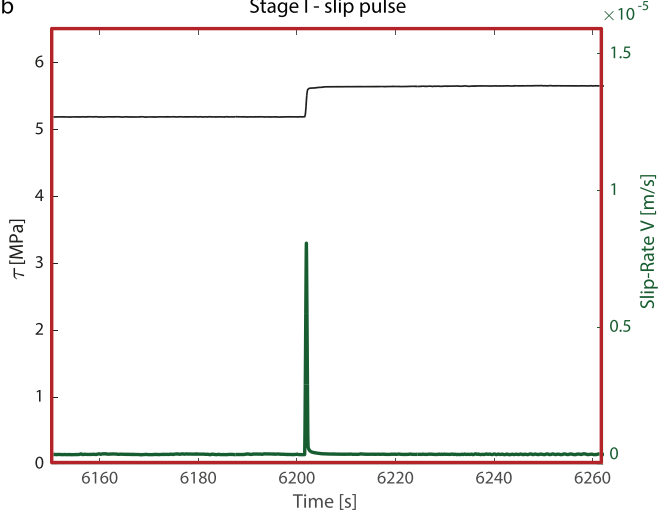

c

Stage II - slip bursts
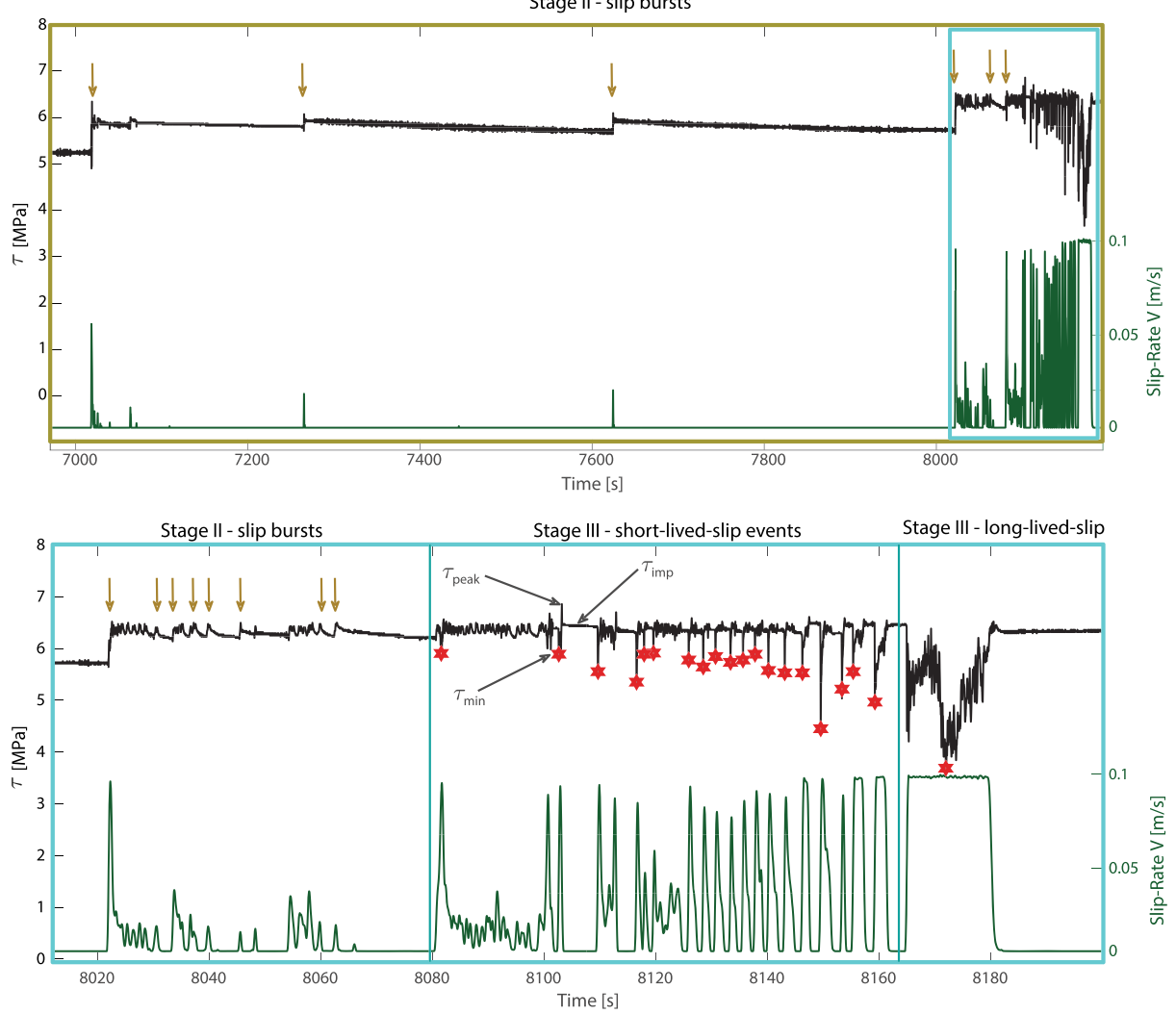

Figure 4. Experiment s1409 performed under room-humidity conditions. (a) Shear stress $\tau$ and slip-rate V versus time. (b) Zoom of the slip pulse associated to a shear stress perturbation during stage I. (c) Zoom on the slip bursts (ocher arrows) during stage II. (d) Zoom of the series of short-lived slip events and single long-lived slip event corresponding to stage III. The red stars indicated the minimum shear stress reached at each event $\tau_{\min }$.

coefficient $\mu$ with the evolution of the slip-rate $V$ (Figure 6) performing comparative analyses of the system (fault + apparatus) behavior at the onset of unstable frictional (slip) events. For the experiments performed under room-humidity conditions and in presence of $100 \%$ distilled water (Figure 6a), we observed an exponential decay of $\mu$ with $V$ once a critical slip-rate $V_{w}$ of $0.040 \mathrm{~m} / \mathrm{s}$ for room humidity conditions and $0.042 \mathrm{~m} / \mathrm{s}$ for pressurized water was overcome (Figure 6a). Instead, in the experiments performed with fluids with higher viscosities, the slip rate for weakening scattered from $0.04 \mathrm{~m} / \mathrm{s}$ to the maximum target $V$ of $0.1-0.12 \mathrm{~m} / \mathrm{s}$ and the decay of $\mu$ had a poor dependence with $V$ (Figure 6b). These differences in the critical (weakening) slip rate and $\mu$ decay imply that the fluid viscosity affects the type of fault weakening mechanism during the experimental seismic sequence. 


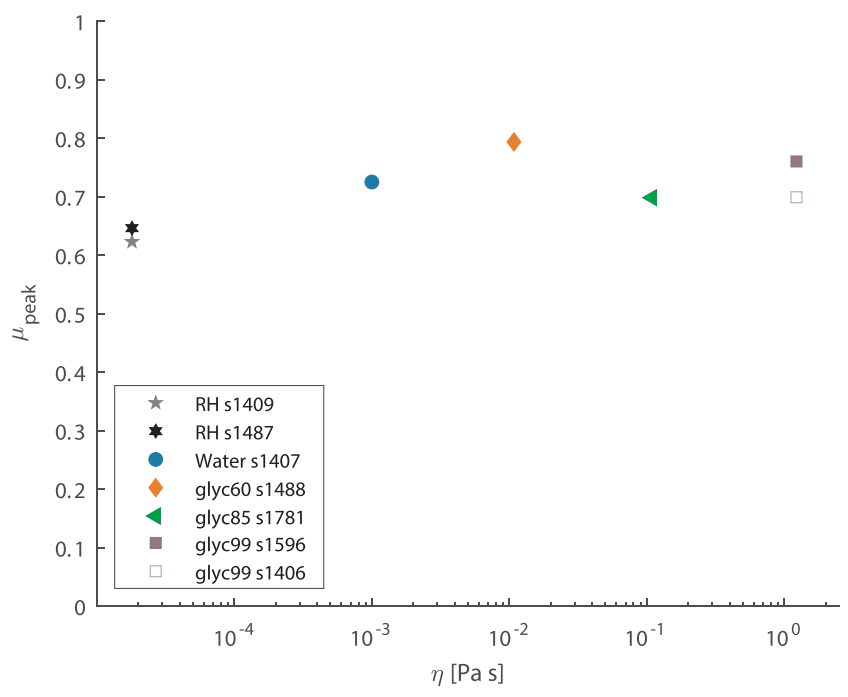

Figure 5. Peak friction coefficient versus viscosity of the fluid on the slipping surface. For the experiments performed under room humidity conditions, the viscosity of the air $\left(\eta=1.88 \times 10^{-5}\right)$ trapped in the slip zone was used. The unstable behavior of the experimental fault occurred at an effective friction coefficient of $0.71 \pm 0.04$, independently of the viscosity of the fluid.

\section{Discussion}

According to mechanical data and regardless of the viscosity of the fluid, fault reactivation occurred at $\mu \approx 0.71$ (Figure 5) compatible with the Byerlee friction law (Byerlee, 1978).

To understand the influence of fluid viscosity on the first two stages, we compared the mechanical results in terms of recorded slip-rate $V$ and slip $U$. For stage I, the number of the slip pulses is directly linked to the number of shear stress steps performed during the experiment. Indeed, every shear step triggered a single slip pulse (Table 2). The maximum slip rate reached during the pulse is independent of the fluid viscosity. During stage II the number of the slip bursts is independent of the number of shear steps required to reach the fault reactivation. Indeed, several slip bursts happened during a shear step. However, both the number of slips burst and the maximum slip velocity reached during these events at stage II are independent of the fluid viscosity (Table 2).

\subsection{Fault Weakening Mechanisms}

Given the presence of fluids, the low imposed effective stresses, the room temperature experiments, the possible fault weakening mechanisms that can be activated in these experiments are flash heating (FH), thermal pressurization (TP), and elastohydrodynamic (EHD) lubrication (see also Cornelio et al., 2019 for the discussion). In the discussion below we also included the dependence of viscosity with temperature for the cases where viscosity is explicitly involved, TP and EHD.

The FH mechanism is a weakening process acting on a fault surface due to the local increase of the temperature of the asperities populating the sliding surface with consequent reduction of the frictional strength (Beeler et al., 2008; Goldsby \& Tullis, 2011; Passelègue et al., 2014; Rice, 2006). The macroscopic evolution of the shear stress $\tau$ can be written as a function of the slip velocity following:

$$
\tau=\left[\left(\mu_{\text {peak }}-\mu_{\mathrm{w}}\right) \frac{V_{w}}{V}+\mu_{\mathrm{w}}\right] \sigma_{n}
$$

where $\mu_{\text {peak }}=0.71$ is the friction coefficient (Figure 5), $\mu_{w}$ is the friction coefficient at the weakened state, $V_{w}$ is the critical weakening velocity allowing thermal degradation of asperities during their contact lifetimes, and $\sigma_{\mathrm{n}}$ is the normal stress. If the predicted minimum shear stress (or friction coefficient) from equation (2) is similar to the measured one, the weakening mechanism is likely FH. For Westerly granite, $\mu_{w}=0.1-0.2$ (Cornelio et al., 2019; Goldsby \& Tullis, 2011; Passelègue et al., 2014) and, based on our experimental evidence, $V_{w}$ slightly increased from $V_{w}=0.040 \mathrm{~m} / \mathrm{s}$ under room humidity conditions to $V_{w}=0.042 \mathrm{~m} / \mathrm{s} \mathrm{in}$ the presence of pressurized fluids (Figure 6a). This result is in agreement with the experiments conducted on silicate rocks in the presence of water that demonstrated a cooling effect of water on the asperities which delayed or even buffered the activation of flash heating and weakening mechanisms (Acosta et al., 2018; Passelègue et al., 2016; Violay et al., 2014, 2015). Based on the flash heating model (Rice, 2006) we can estimate the asperity diameter $D=\frac{\pi \alpha}{V_{w}}\left[\frac{\rho C\left(T_{w}-T_{0}\right)}{\tau_{c}}\right]^{2}{ }^{2} 13 \mu \mathrm{m}$, where $\alpha=1.2510^{-6} \mathrm{~m}^{2} \mathrm{~s}^{-1}$ is the thermal diffusivity, $\rho=2650 \mathrm{~kg} \mathrm{~m}^{-3}$ rock density, $C=900 \mathrm{Jkg}^{-1} \mathrm{~K}^{-1}$ is the heat capacity, $T_{w}=900^{\circ} \mathrm{C}$ is the weakening temperature, $T_{0}=25^{\circ} \mathrm{C}$ is the initial temperature, and $\tau_{c}=5.610^{9} \mathrm{~Pa}$ is the contact stress (data for Westerly granite; Passelègue et al., 2014). According to equation (2), the fast decrease in shear stress measured during experiments conducted under room-humidity and water-saturated conditions can be well explained by flash heating and weakening theory (Figures $7 \mathrm{a}$ and $7 \mathrm{~b}$ ). However, the poor fit of the estimated minimum shear stress due to the activation of $\mathrm{FH}$ with respect to the measured one in the experiments conducted with fluids with higher viscosities than distilled water (Figures $6 \mathrm{~b}$ and $7 \mathrm{c}-7 \mathrm{e}$ ) suggests the activation of other fault lubricating mechanisms as discussed below. 
a)

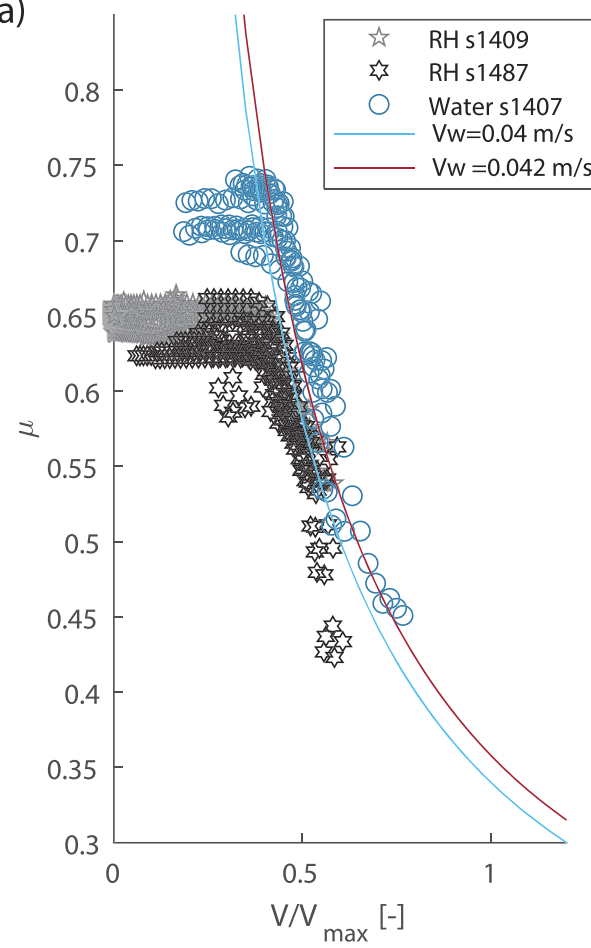

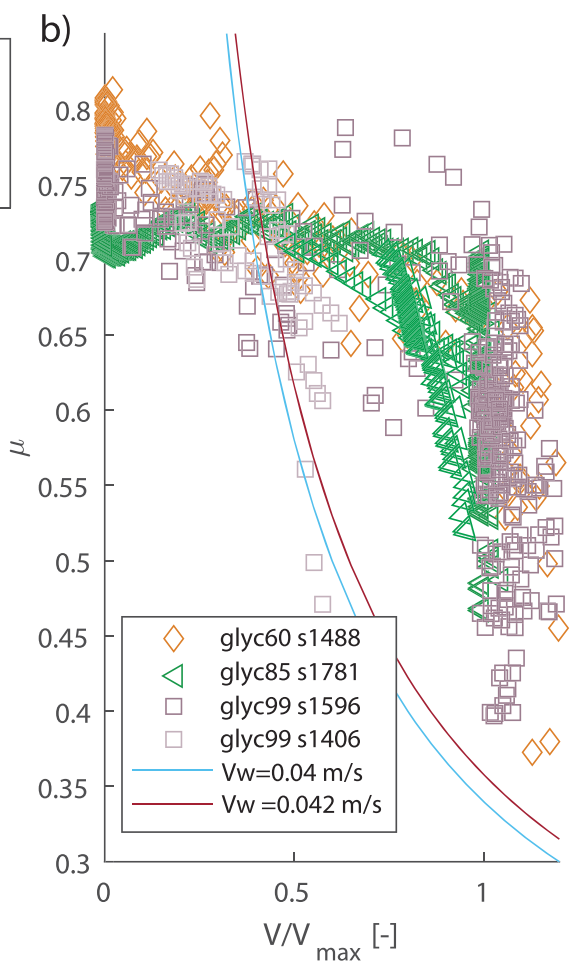

Figure 6. Apparent friction coefficient $\mu$ versus slip-rate $\mathrm{V}$ normalized by the maximum imposed slip rate $\mathrm{V}_{\max }$ $\left(V_{\max }=0.1 \mathrm{~m} / \mathrm{s}\right.$ for all experiments with the exception of $\mathrm{s} 1781$ where $\left.V_{\max }=0.2 \mathrm{~m} / \mathrm{s}\right)$. (a) For the experiments performed in room-humidity conditions (black and grey in color stars) and in presence of distilled water (blue dots), we observed an exponential decay of $\mu$ with V. (b) For the experiments performed with fluids with higher viscosities than water (orange diamonds for experiment performed in presence of mixture $60 \%$ glycerol $/ 40 \%$ water, green triangles for experiment with $85 \%$ glycerol/15\% water, and pale and dark purple squares for the two experiments with $99 \%$ glycerol), we did not recognize a systematic relationship between $\mu$ and $\mathrm{V}$.

To quantify the mismatch (Figure 7) during stage III between the minimum shear stress measured in the experiments and the estimated shear stress due to FH (equation (2)), we computed the percent error between the two shear stresses. The percent error is computed as the average of the absolute difference between the estimated values of shear stress $\tau_{\min , \text { pred }}$ and the experimental values $\tau_{\text {min,meas }}$ divided by the experimental values $\tau_{\text {min,meas }}$ for each short-lived slip-event " $i$ ”:

Table 2

Slip Pulse and Slip Burst Analysis

\begin{tabular}{lllllll}
\hline \multicolumn{7}{c}{ Stage I } \\
\hline Experiment & Condition & N.steps & No. of slip pulses & $\begin{array}{l}\text { Maximum slip } \\
\text { rate }\left(10^{-5} \mathrm{~m} / \mathrm{s}\right)\end{array}$ & No. of slip bursts & $\begin{array}{l}\text { Maximum slip } \\
\text { rate }(\mathrm{m} / \mathrm{s})\end{array}$ \\
\hline s1409 & RH & 14 & 11 & 8.24 & 13 & 0.048 \\
s1487 & RH & 13 & 11 & 5.07 & 3 & 0.058 \\
s1407 & H2O & 14 & 12 & 5.45 & 1 & 0.021 \\
s1488 & glyc60 & 15 & 12 & 6.01 & 4 & 0.012 \\
s1781 & glyc85 & 15 & 13 & 4.74 & 2 & 0.014 \\
s1596 & glyc99 & 14 & 10 & 3.24 & 2 & 0.173 \\
s1406 & glyc99 & 14 & 12 & 1.21 & 0 & - \\
\hline
\end{tabular}

Note. N.steps are the shear stress step before stage III. For each experiment, the number of recorded slip pulse during stage I, the maximum recorded slip rate, the number of slip bursts during stage II, and the related maximum slip rate are reported. 
a)

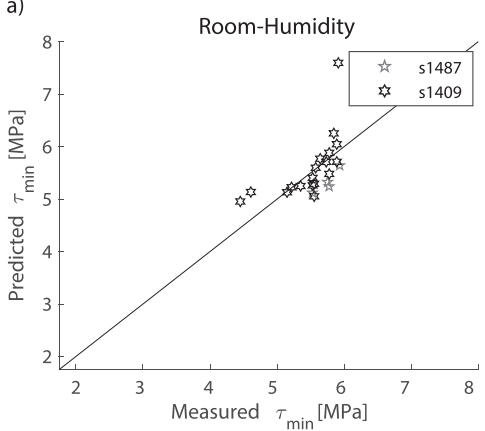

d)

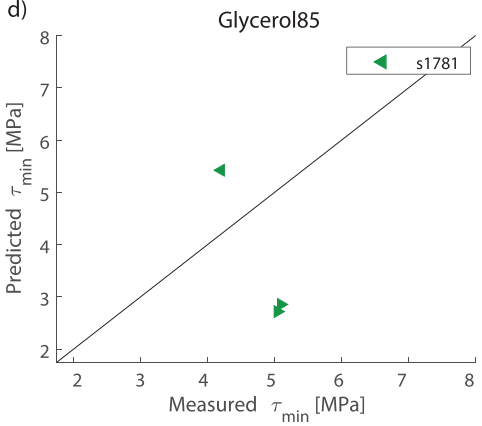

b)

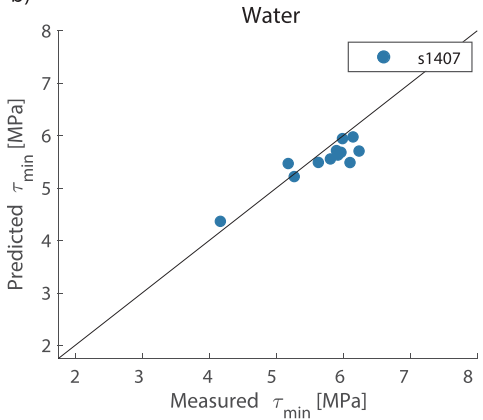

c)

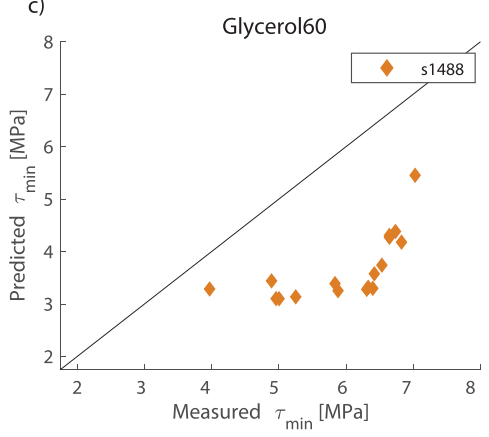

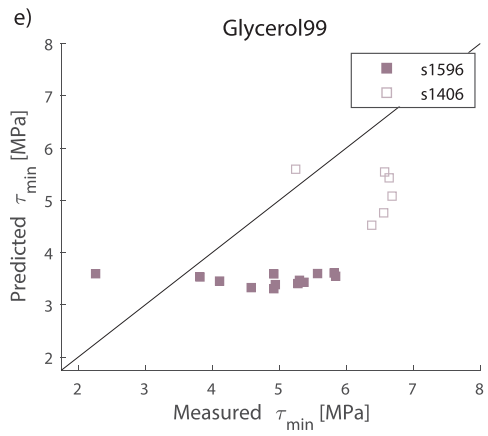

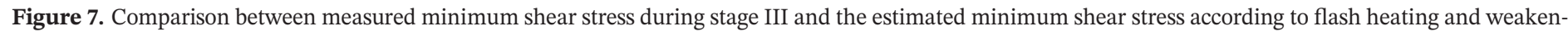

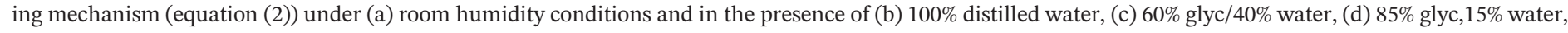

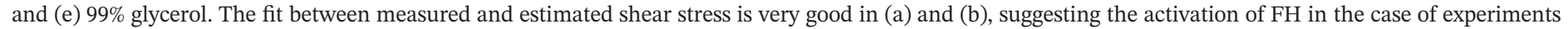

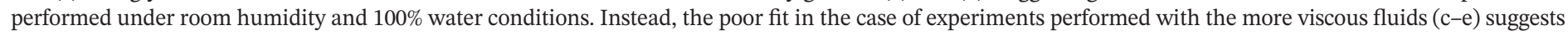
the activation of other fault lubricating mechanism than FH (see discussion and Figures 8, 9, and 11).

$$
\text { Percent error }=\frac{\sum_{\mathrm{i}=0}^{\mathrm{n}}\left(\frac{\left|\tau_{\text {min,pred }}-\tau_{\text {min,meas }}\right|}{\tau_{\text {min,meas }}}\right)_{i}}{n} \text {, }
$$

where $n$ is the number of short-lived slip events for each experimental condition.

In the case of $\mathrm{FH}$, the mismatch between the minimum shear stress estimated with equation (2) and the measured shear stress increases from approximately $4 \%$ for the experiments conducted with water to approximately 52\% for the experiments conducted with 99\% glycerol (see summary in Figure 11 below).

The TP mechanism assumes that fluids present in the fault have an expansion coefficient higher than that of rocks (Rice, 2006; Sibson, 1973). Because of the temperature increase due to frictional heating, the fluid pressure increases and induces a reduction of the effective normal stress acting on the fault. If this mechanism was triggered in our experiments, it would localize on the slipping zone (= between the two sliding surfaces of Westerly granite), since we performed our experiments under drained conditions and no fluid overpressure was recorded at the pump during testing (Figure 3).

Thermal pressurization can be described by the following equations (Rice, 2006):

$$
\begin{gathered}
\frac{\partial T}{\partial t}=\frac{1}{(\rho c)_{e f \mathrm{f}}} \mu_{0}\left(\sigma_{n}-P_{f}\right)\left(\frac{v}{2 w}\right)+\alpha_{t h} \frac{\partial^{2} T}{\partial y^{2}} \\
\frac{\partial P_{f}}{\partial t}=\frac{\lambda_{f}-\lambda_{r}}{\beta_{f}+\beta_{r}} \frac{\partial T}{\partial t}+\alpha_{h y} \frac{\partial^{2} P_{f}}{\partial y^{2}}
\end{gathered}
$$

where $y$ is axes perpendicular to the fault plane, $\rho$ is the rock density, $c$ is the rock specific heat, $\mu_{0}$ is the peak friction coefficient $\left(\tau_{\mathrm{imp}} /\left(\sigma_{\mathrm{n}}-\mathrm{P}_{\mathrm{f}, \mathrm{imp}}\right)\right), V$ is the slip rate, $\alpha_{t h}$ is the thermal diffusivity of the fluid, $\lambda$ is the isobaric thermal expansion coefficient, and $\beta$ is the compressibility (subscripts $f$ and $r$ stand for fluid and rock, 
Table 3

Thermal and Hydraulic Properties Used in the Thermal Pressurization Model and in the Heat Diffusion Model

\begin{tabular}{llllll}
\hline & Water $^{\mathrm{a}}$ & glyc60 $^{\mathrm{b}}$ & glyc85 $^{\mathrm{b}}$ & glyc99 $^{\mathrm{b}}$ & $\mathrm{WG}^{\mathrm{c}}$ \\
\hline$\kappa[\mathrm{W} /(\mathrm{mK})]$ & 0.6 & 0.38 & 0.31 & 0.25 & 3.07 \\
$\lambda\left[10^{-3}\right]$ & 1.21 & 1.93 & 2.23 & 2.41 & 0.02 \\
$\beta\left[10^{-10} \mathrm{~Pa}^{-1}\right]$ & 5.1 & 3.37 & 2.65 & 2.1 & 14.9 \\
$\eta_{\mathrm{o}}[\mathrm{Pa} \mathrm{s}]$ & 0.001 & 0.01 & 0.109 & 1.226 & - \\
$\rho\left[\mathrm{kg} \mathrm{m}^{-3}\right]$ & 1000 & 1151 & 1219 & 1255 & 2650 \\
$C\left[\mathrm{~J}(\mathrm{~kg} \mathrm{~K})^{-1}\right]$ & 4180 & 3121 & 2678 & 2430 & 900 \\
\hline
\end{tabular}

Note. $\kappa=$ thermal conductivity, $\lambda=$ thermal expansion coefficient, $\beta=$ compressibility coefficient, $\eta_{0}=$ initial viscosity, $\rho=$ density, $C=$ specific heat, $\mathrm{WG}=$ Westerly granite.

${ }^{\mathrm{a}}$ Thermal properties of water from Goranson (1942). ${ }^{\mathrm{b}}$ Thermal properties of water/glycerol mixtures from Bates (1936). ${ }^{\mathrm{C}}$ Thermal properties of Westerly granite from Eppelbaum et al. (2014). respectively). The hydraulic diffusivity of the fault is expressed as a function of the fault's permeability $(K)$ and the fluid viscosity $(\eta)$ with $\alpha_{h y}=K /\left(\eta(T) \beta_{f}\right)$. We compared the measured minimum shear stress of each slip event triggered in the presence of viscous fluids in our experiments with the theoretical estimated minimum shear stress associated to the TP mechanism via equations $4 \mathrm{a}$ and $4 \mathrm{~b}$. The minimum shear stress due to TP was estimated using a coupled Finite Element Analysis 2-D time-dependent model in @Matlab. In this model, we computed both the heat source and its dissipation in time and space. We considered a 2-D sample $(50 \times 55 \mathrm{~mm}$, or the diameter versus height of each cylinder of Westerly granite), an initial effective normal stress of $10 \mathrm{MPa}$ (the one imposed the experiments) and a friction coefficient equal to the $\mu_{\text {peak }}$ (Figure 5) and included the presence in the slipping zone of a viscous fluid. Fluid viscosity coincides with the experimental one (see Table 3). Two different materials were used to simulate the slipping zone and the bulk material (Westerly granite). The thermal and hydraulic properties of the slipping zone were defined as a linear combination of the thermal properties of the fluid and of the rock. Except for temperature dependency on fluid viscosity, the fluids and rock properties were considered constant during the modeled experiments and are reported in Table 3. We applied the empirical formulation proposed by Cheng (2008) to correct the lubricant viscosity with the temperature estimated in the model (note that glycerol acts as a Newtonian fluid at the investigated slip rates). The permeability evolution of the slip zone cannot be measured in the experiment and it was considered constant and equal to $K=10^{-13} \mathrm{~m}^{2} / \mathrm{s}$ (Ye \& Ghassemi, 2018). This assumption is considered valid since negligible shortening (and consequently dilation) variation was measured during the experiments and no off-fault damage was observed on postmortem samples. The permeability of the bulk material $K=10^{-19} \mathrm{~m}^{2} / \mathrm{s}$ (Acosta et al., 2018; Nasseri et al., 2009). The bulk material was regarded as very low porous media ( $3 \%$ porosity, measured with the helium pycnometer), whereas the initial porosity on the fault plane is defined as $\phi=1-A_{\mathrm{r}} / A=0.95$, where $A_{\mathrm{r}}$ is the real contact area and $A$ is the nominal area of the slip surface. In the model, the experimental fault is sheared at the recorded slip-rate $V(\mathrm{t}, \mathrm{r})$ over a thin slip zone of thickness $2 w=50 \mu \mathrm{m}$ equal to the initial height of the asperities (see Figure 1). We assumed that all the mechanical energy is dissipated as heat and no heat is lost by radiation, so the heat flux $Q(r, t)=0.5 \cdot \tau(t) \cdot V(r, t)$ is function of time $t$ and the the radial distance $r$ from the center of the sample. A Neumann boundary condition was applied to the bottom external edge of the model (i.e., slip zone in Figure 8 a) to consider the flux of heat due to shearing and the coupled increase of fluid pressure. On the other three external boundaries, a constant temperature $T=293.15 \mathrm{~K}$ as the initial temperature of the two materials and a constant pressure $P=0.1 \mathrm{MPa}$ for the bulk material and an initial fluid pressure $P=2.7 \mathrm{MPa}$ for the slipping zone were imposed. At the inner boundary between the slip zone and the wall rock, the continuity of the solution was granted.

According to our simulations, the estimated minimum shear stress associated to TP mechanism at $2 / 3$ of the sample radius (maximum effect) is not consistent with the minimum shear stress measured in the experiments (Figure 8c). Indeed, TP mechanism would result in (1) larger shear stress drops and (2) smaller minimum shear stress compared to the measured ones (Figure 9). Importantly, the mismatch between the minimum shear stress estimated with the thermal pressurization model and the measured minimum shear stress is at least 35\%, independently of the viscosity of the fluid (see Figure 11b). According to the Finite Element Analysis 2-D model, the activation of TP is not consistent with the experimental evidence.

Instead, the minimum shear stress measured in the experiments conducted with fluids with higher viscosities than water could result from the activation of EHD. EHD is a weakening mechanism induced by overpressure generated by the shearing of a thin viscous fluid between two subparallel and rough surfaces (e.g., the experimental faults). Here we test this hypothesis using the model proposed by Brodsky and Kanamori (2001) and refined by Bizzarri (2012). The model is parameterized using the Sommerfeld number, which is a measure of the lubrication pressure normalized by the normal stress. The fault shear strength dependence with the Sommerfeld numbers $S_{0}$ can be expressed as (Bizzarri, 2012; Brodsky \& Kanamori, 2001) 


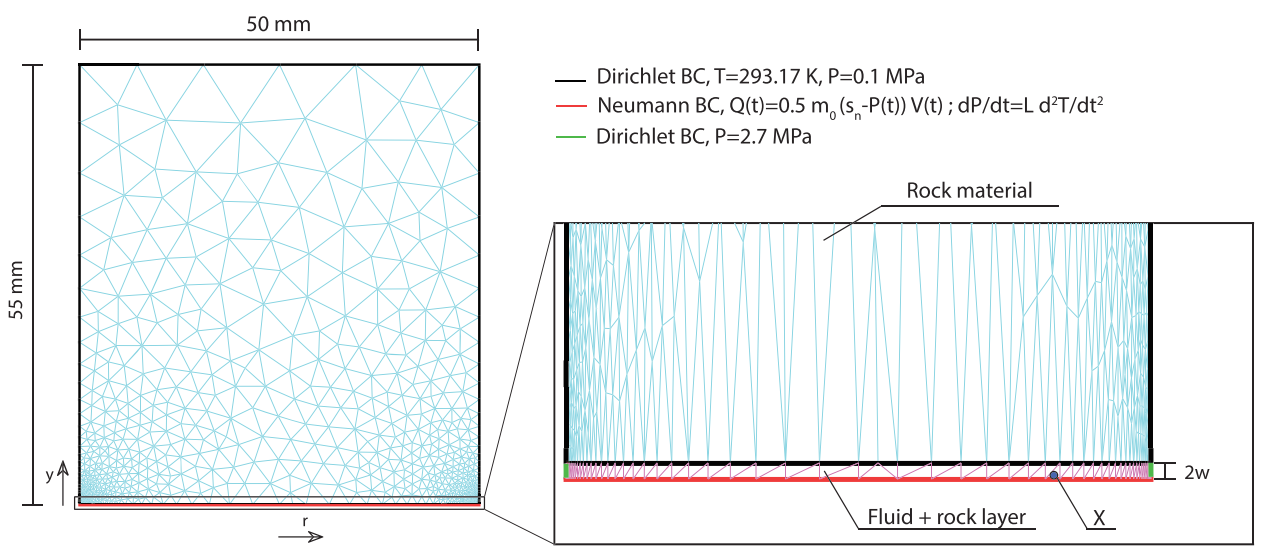

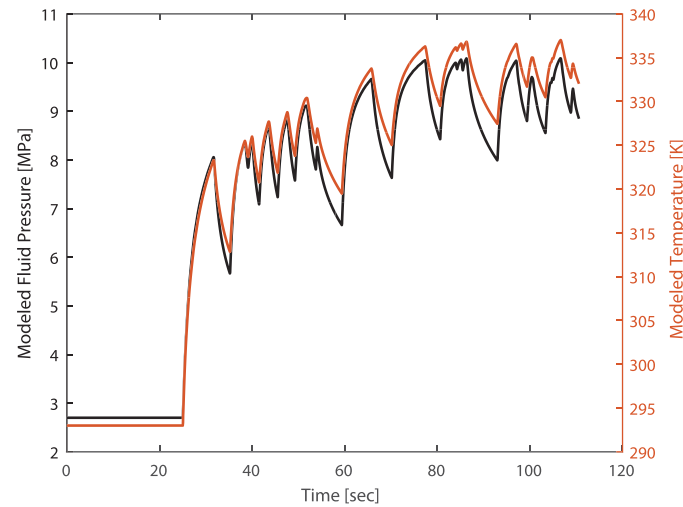

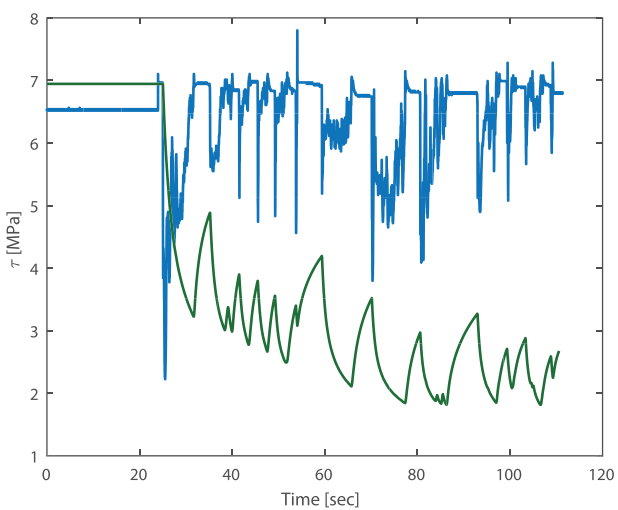

Figure 8. Thermal pressurization (TP) model geometry and results. (a) Mesh and boundary conditions of the model with zoom on the slipping zone. (b) Temperature and fluid pressure distribution for the experiment s1596 (glyc 99\%) during stage III on the point X $(\mathrm{r}, \mathrm{y})=(16.7,0 \mathrm{~mm})$. (c) Measured shear stress (blue curve) and modeled shear stress (green curve) using the TP model.

$$
\tau(S)=\left\{\begin{array}{c}
\mu_{\text {static }} \sigma_{\text {eff }}+\frac{w}{u} P_{\text {lub }}, \quad S_{0}<1 \\
\frac{w}{u} P_{\text {lub }}, \quad S_{0} \geq 1
\end{array}\right.
$$

where $S_{0}=\left(P_{f}-P_{l u b}\right) / \sigma_{n}$ is the Sommerfeld number, $P_{l u b}=6 \eta r U^{2} V /(2 w)^{3}$ is the lubricant pressure, $\eta$ is the viscosity of the fluid, $r=0.001$ (Brodsky \& Kanamori, 2001) is the dimensionless roughness, $U$ is the slip distance, $w$ is the average thickness of the slurry film, and $V$ is the measured slip rate. The Sommerfeld number describes the transition between three lubrication regimes (boundary, mixed, or fully lubricated regimes) which are associated to the evolution of the strength of the fault. Unfortunately, a key parameter of the EHD model is the evolution of $w$ with time and slip which is poorly constrained because it can only be measured before and at the end of the experiment. For this reason, differently to previous studies (Bizzarri, 2012), we assumed $w$ proportional to the measured shortening $\delta$, following the relation: $w=w_{0}+\delta$. We performed a 2-D Finite Element diffusion analysis to estimate the average temperature of the fluid trapped between the slip surfaces and the viscosity was corrected for temperature increase as described in Cornelio et al. (2019). In particular, we used the sample geometry (Figure 8a) and the same fluid properties (Table 3) of the model used for the TP but in the EHD model the fluid pressure is considered constant and equal to the imposed one measured by the fluid pressure transducers (Table 1). Using the average estimated temperature in the slip zone at $2 / 3 R(R=25 \mathrm{~mm}$ is the external radius of the sample), we corrected the initial viscosities (at 
a)

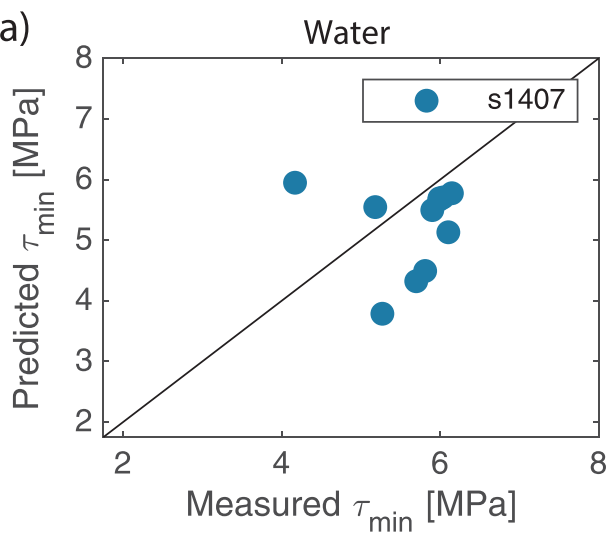

c)

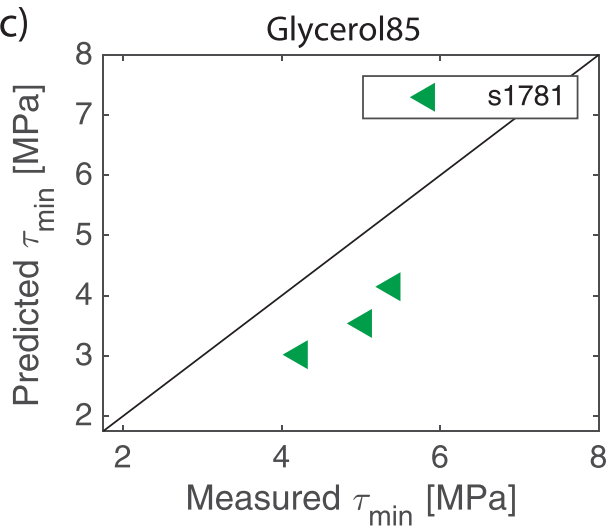

b)

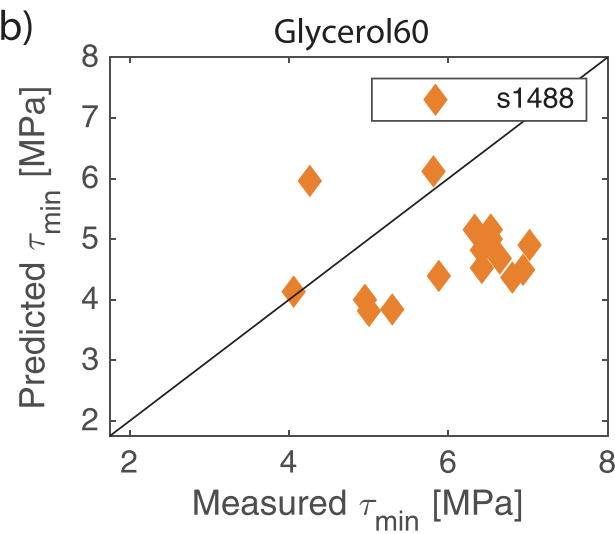

d)

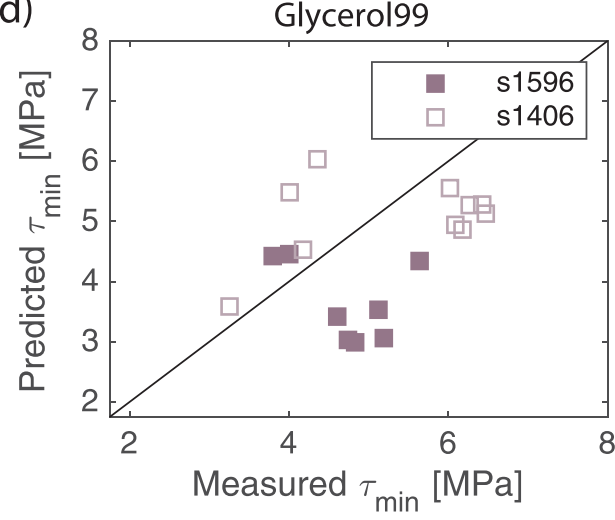

Figure 9. Comparison between experimental minimum shear stress and the predicted minimum shear stress by TP models in presence of (a) water, (b) $60 \%$ glyc/40\% water, (c) $85 \%$ glyc/15\% water, and (d) $99 \%$ glycerol. The poor fit of the experimental data with the estimates of minimum shear stress according to the Finite Element Analysis 2-D model suggest that TP mechanism was never activated in the experiments discussed here.

$20^{\circ} \mathrm{C}$ ) from the increase of temperature of the fluids due to frictional heating exploiting the empirical law proposed by Cheng (2008) for water/glycerol mixtures. The dynamic viscosity $\eta$ of the mixture is

$$
\eta=\eta_{\mathrm{w}}^{\zeta} \cdot \eta_{\mathrm{glyc}}^{1-\zeta}
$$

where $\zeta$ is the weighting factor, function of the concentration of glycerol $C_{\mathrm{m}}$ and of two empirical factors $a$ and $b$ which are dependent of the temperature $T$

$$
\zeta=1-C_{\mathrm{m}}+\frac{a(T) \cdot b(T) \cdot\left(1-C_{\mathrm{m}}\right)}{a(T) \cdot C_{\mathrm{m}}+b(T) \cdot\left(1-C_{\mathrm{m}}\right)}
$$

Our model estimates of the minimum shear stress induced by EHD matched well the measured ones in the case of the experiments performed with mixtures of $40 \%$ water $/ 60 \%$ glycerol and $15 \%$ water $/ 85 \%$ glycerol for all the slip events occurring at cumulated slips larger than 0.25 and $0.015 \mathrm{~m}$ (after the main first event), respectively (Figures 10b and 10c). In particular, the misfit between measured and modeled minimum shear stress decreases from approximately $52 \%$ for the experiments conducted with $100 \%$ distilled water to approximately $9 \%$ for the experiment conducted with 99\% glycerol (Figure 11c). Moreover, EHD explains well all the stress drops recorded during the two experiment performed in the presence of a highly viscous fluid (99\% glycerol; Figure 10d). We conclude that FH is probably favored for low-viscosity $(<1 \mathrm{mPa}$ s) fluids and room-humidity conditions, whereas EHD is the dominant weakening mechanisms in the case of fluids with higher viscosities than water. 
a)

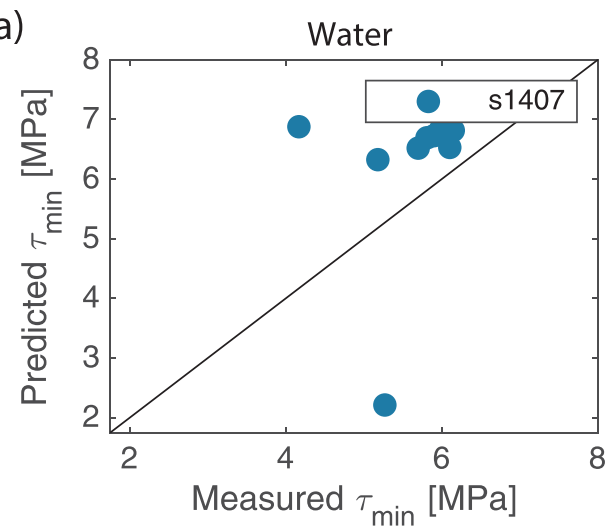

c)

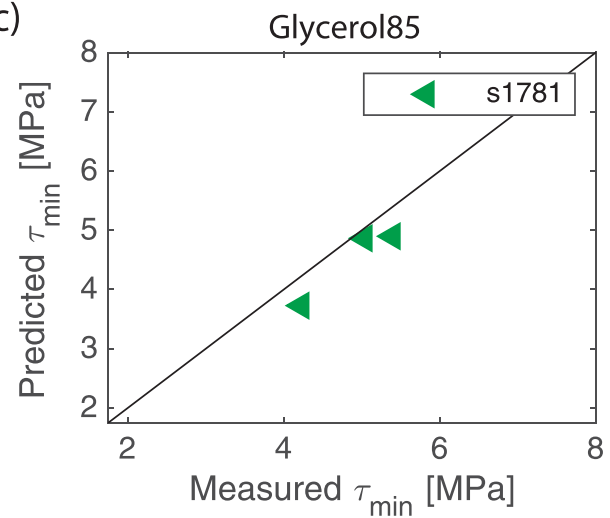

b)

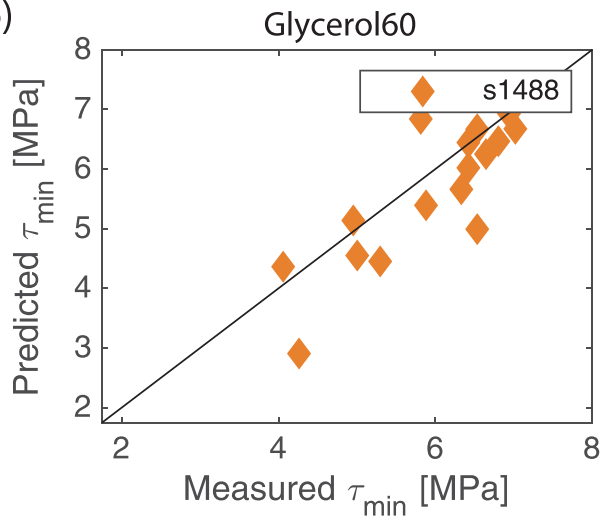

d)

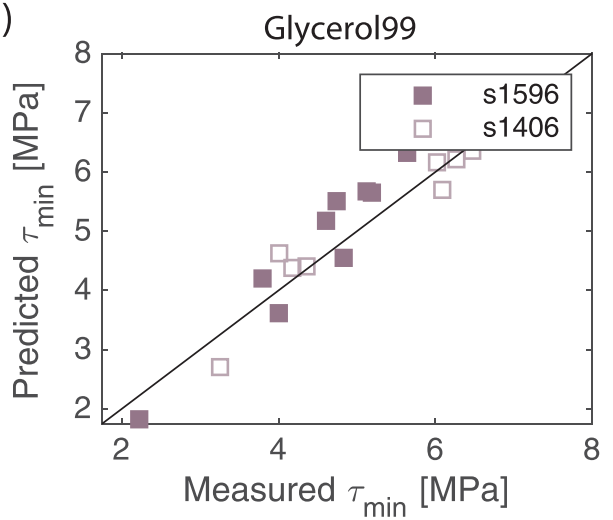

Figure 10. Comparison between minimum shear stress measured in the experiments and estimated in Finite Element Analysis 2-D EHD models in the presence of (a) 100\% distilled water, (b) $60 \%$ glyc/40\% water, (c) $85 \%$ glyc/15\% water, and (d) $99 \%$ glycerol. The viscosity of the fluids was corrected for its temperature dependence (see main text). Note the good fit between measured and estimated minimum shear stress in the case of the experiments performed with the more viscous fluids. The good fit (b-d) and quantified in the diagram of Figure 11c, suggests that EHD mechanism could operate in these experiments.

\subsection{Estimation of the Breakdown Work}

The main outcome of the modeling and analysis presented in the previous section is that two mechanisms (FH and EHD) are activated during our experiments depending on the presence of fluids and their viscosities (Figure 11). Here we question if the type of weakening mechanism influences the amount of breakdown work dissipated during earthquake rupture propagation. Indeed, the activation of FH and EHD mechanisms have been invoked to estimate the breakdown work ( $W_{b}$ or energy dissipated in the breakdown zone during seismic rupture propagation) in earthquake energy budgets (Brantut \& Viesca, 2017; Cornelio et al., 2019; Rice, 2006). Therefore, we computed the breakdown work dissipated during both the short- and the longlived slip events of stage III (Figure 4c). The $W_{b}$ was calculated by integrating the evolution of shear stress with slip (Palmer \& Rice, 1973):

$$
W_{b}=\int_{U_{\text {in }}}^{U_{\text {min }}}\left(\tau(U)-\tau_{\min }\right) d U
$$

where $U_{\min }$ is the slip distance at which the measured shear stress is equal to $\tau_{\min }$ and $U_{\text {in }}$ is the slip distance at the beginning of the short- or long-lived slip events. For each slip event and independent of the presence and the viscosity of the fluid, $W_{b}$ increased with slip following a power law relationship (Figure 12). A similar trend between $W_{b}$ and slip distance has been attributed to thermal pressurization by Viesca and Garagash (2015), suggesting that TP could be an effective weakening mechanism under conditions of low fluid viscosity and high normal stress. However, EHD is more efficient for high viscous fluids and at low normal stresses. This trend is very similar to the one measured in experiments performed on Westerly granite either 
a)

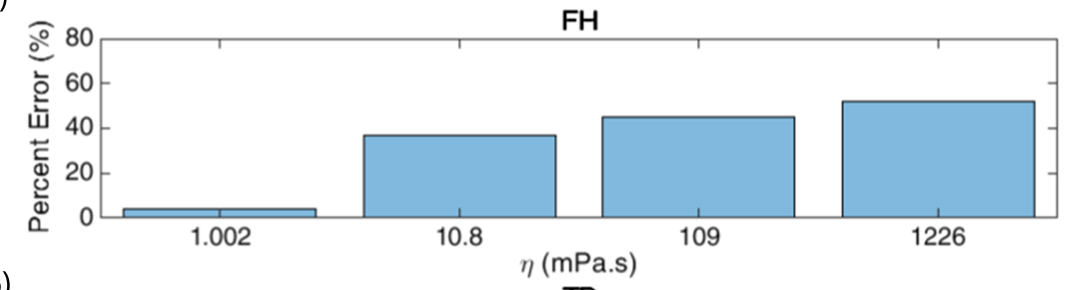

b)

TP

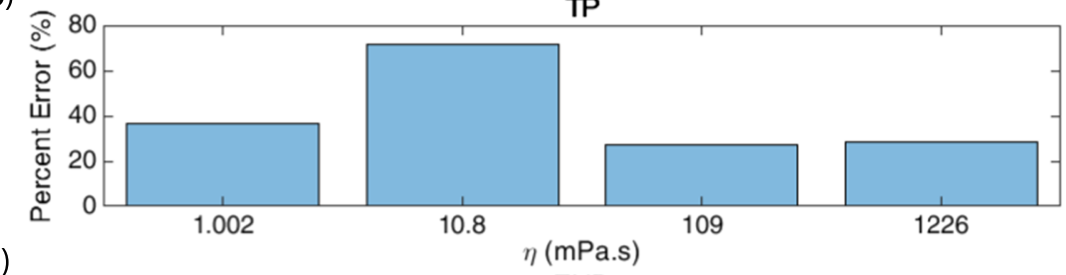

EHD

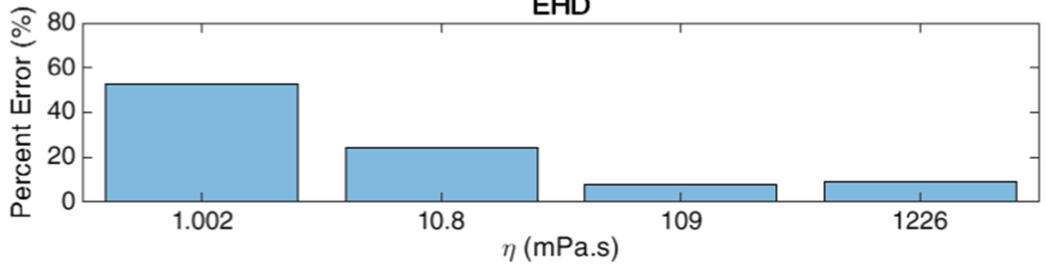

Figure 11. Misfit or percent error (see equation (3)) between the measured minimum shear stress and the estimated one for (a) Flash heating (FH), (b) Thermal pressurization (TP), and (c) elastohydrodynamics (EHD) (see main text for discussion). According to this analysis, FH occurred only in the experiments performed with $100 \%$ distilled water, and EHD in the experiments performed with glycerol. Instead, modeling suggests that TP was never activated in the experiments.

a)

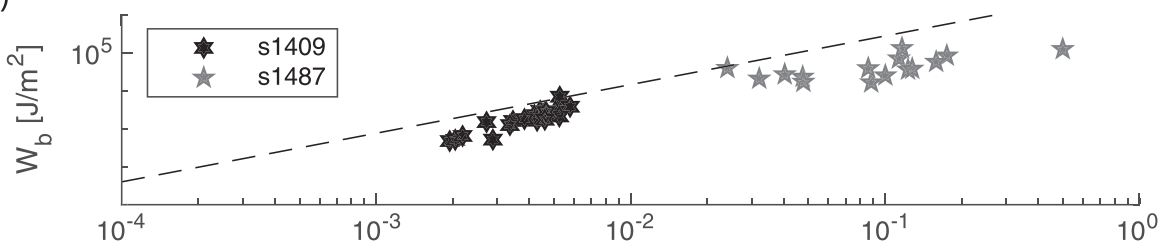

b)

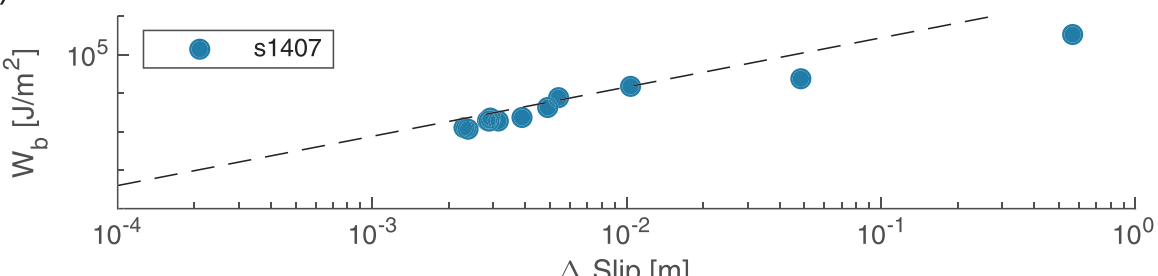

C)

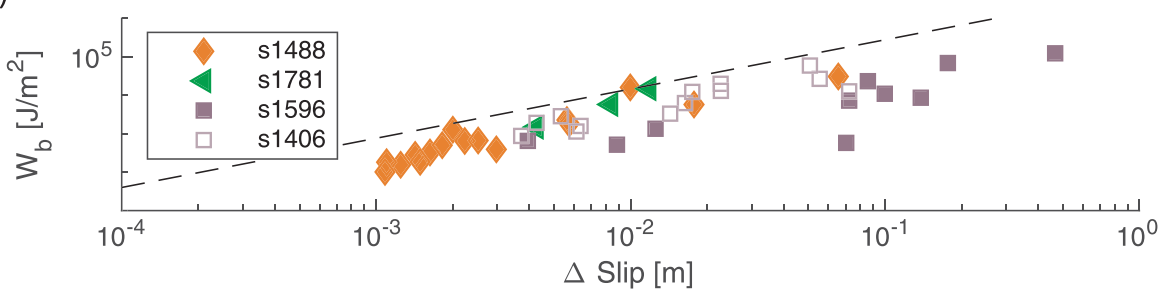

Figure 12. Breakdown work versus the $\Delta U=U_{\min }-U_{\text {in }}$ for short-lived and long-lived events under (a) room humidity conditions (black and grey stars), (b) in the presence of water (blue dots), and (c) in presence of $60 \%$ glycerol $/ 40 \%$ water mixtures (orange diamonds), $85 \%$ glycerol/15\% water mixtures (green triangles), and $99 \%$ glycerol (purple squares). 

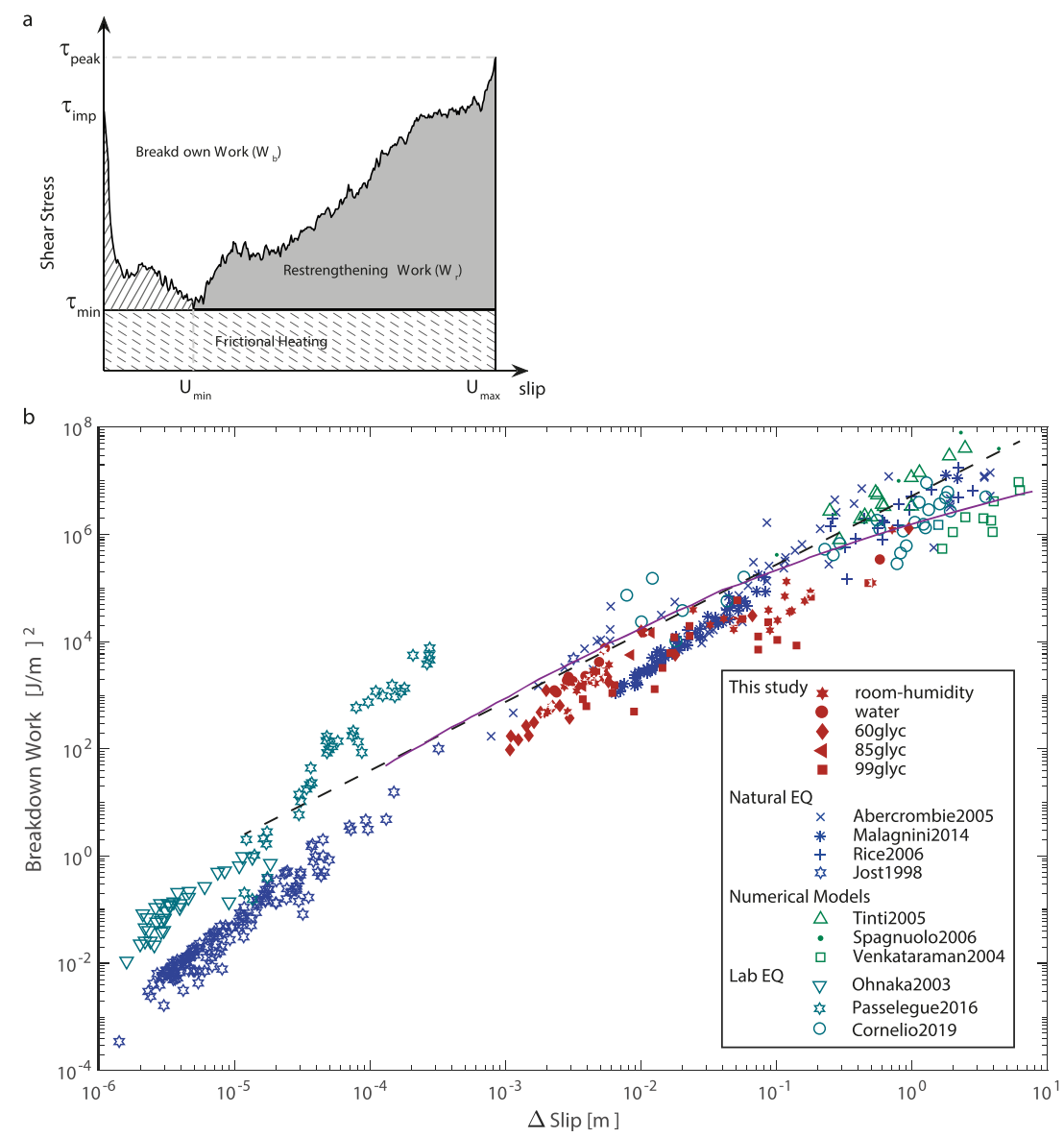

Figure 13. Energy budget and breakdown work in experimental and natural earthquakes. (a) Schematic representation of the shear stress versus slip distance and energy partitioning during the first short-lived slip events of the experiment s1488 performed in presence of a mixture $60 \%$ glycerol $/ 40 \%$ water. The area indicated by inclined segments below the curve connecting $\left(\tau_{\mathrm{imp}}, 0\right)$ and $\left(\tau_{\min }, \mathrm{U}_{\min }\right)$ corresponds to the breakdown work $\mathrm{W}_{\mathrm{b}}$. The light grey area between $\left(\tau_{\min }, \mathrm{U}_{\min }\right)$ and $\left(\tau_{\text {peak }}, \mathrm{U}_{\max }\right)$ is the restrengthening work $\mathrm{W}_{\mathrm{r}}$ (not discussed in this study). The dashed lines area $\left(\tau_{\min }, 0\right) \times\left(\tau_{\min }\right.$, $\mathrm{U}_{\text {max }}$ ) is the minimum frictional heat dissipated during sliding (Kanamori \& Rivera, 2006). (c) Experimental and seismological estimates of breakdown work. The red symbols correspond to the $\mathrm{W}_{\mathrm{b}}$ for the short- and long-lived slip events during stage III (see Figure 4) presented in this study. Blue symbols correspond to seismological estimates of $\mathrm{W}_{\mathrm{b}}$ for natural (Abercrombie \& Rice, 2005; Malagnini et al., 2014; Rice, 2006) and induced earthquakes (Jost et al., 1998). Green symbols correspond to seismological estimates of $\mathrm{W}_{\mathrm{b}}$ from numerical (inversion) models of earthquakes (Spagnuolo, 2006; Tinti et al., 2005; Venkataraman \& Kanamori, 2004); teal-blue symbol are for laboratory estimates of $\mathrm{W}_{\mathrm{b}}$ (Cornelio et al., 2019; Ohnaka, 2003; Passelègue et al., 2017). Dashed black line indicates the best fit proposed by Nielsen, Spagnuolo, Smith, et al. (2016) with $\mathrm{E}=5.25 \times 10^{6} \mathrm{U}^{1.28}$, where $\mathrm{U}$ is the slip distance in meter, and the purple line indicates the solution of the FH model proposed by Brantut and Platt (2017).

under room-humidity conditions in triaxial configuration (Ohnaka, 2003; Passelègue et al., 2016), or in the presence or absence of pressurized fluids in high-velocity rotary shear configuration (Cornelio et al., 2019; Nielsen, Spagnuolo, Violay, et al., 2016), as well as estimated for natural earthquakes (Abercrombie \& Rice, 2005; Malagnini et al., 2014; Rice, 2006), man-induced earthquakes (Jost et al., 1998), and for dynamic source modeling of natural earthquakes (Spagnuolo, 2006; Tinti et al., 2005; Venkataraman \& Kanamori, 2004; Figure 13). In particular, our new data set fits well with the theoretical estimates of the $W_{b}$ associated with fault slip due to flash heating processes (Brantut \& Viesca, 2017), and consistent with the $W_{b}$ estimated for the earthquakes at the KTB deep drilling project (Jost et al., 1998), independently of the activated mechanism in our experiments. Caution should be taken when comparing energies at different scales. On one hand, $W_{b}$ is a quite robust seismological estimate as bias effects are reduced (Guatteri \& Spudich, 2000) but suffers of strong uncertainties related to the signal treatment, to the assumptions made and blurred effects due to rupture-related processes including off-fault damage. On the 
other hand theoretical models used to estimate the breakdown energy for natural and induced seismicity are often oversimplified as many variables like the work dissipated in the surrounding volume through grain crushing, off-fault damage (Cocco et al., 2006; Shipton et al., 2006) is often neglected, considering only the energy necessary to slip on the fault plane. Despite these limitations, the agreement of data across scales as shown in Figure 13 suggests that on average our experiments are pertinent and describe at least some of the frictional instabilities that may occur in nature. In particular, our results suggest that, at least for the experimental conditions discussed here, although two different weakening mechanisms ( $\mathrm{FH}$ and EHD) trigger and control the evolution of dynamic fault strength in laboratory earthquakes, the energy required to weaken the fault for a given earthquake magnitude is independent of the lubrication processes.

\section{Conclusions}

The experiments presented here recognize that, at least at the investigated loading and ambient conditions (room temperature), the viscosity of the fluid does not influence the onset of fault reactivation in fluidpermeated faults (Figure 5). On the other hand, once the fault is frictionally unstable and slip rates accelerate, the fault weakening mechanism that is activated is a function of the fluid viscosity. In particular, under the investigated loading conditions and for the particular roughness of the studied experimental faults, flash heating is active at room humidity conditions and in the presence of low (1 mPa s) viscous fluids (100\% distilled water). Thermal pressurization, as modeled here, is not clearly activated during our experiments. Indeed, EHD is dominant in the presence of high fluid viscosity where EHD prevails over FH. The activation of a particular weakening mechanism does not result in differences in the magnitude of the breakdown work (Figure 12). This might imply that changes in the viscosity of fluids that can be present in fault zones due to previous injection in reservoirs during hydraulic fracturing should not influence the static reactivation of a fault and the breakdown work (if the fluid pressure remains constant), but they might influence the evolution of the associated earthquake sequences in terms of stress drops. A similar analysis in the case of natural earthquake sequences suggest that the activation of preexisting fault due to a quasi-static tectonic load is not influenced by the presence of a viscous fluid that only intervenes to control the way the same amount of energy is released.

\section{Acknowledgments}

This research is funded by SFOE (Swiss Federal Office of Energy) through the EDGAR project. C.C. and M.V. acknowledge EPFL for support. F.X.P. acknowledges funding provided by the Swiss National Science Foundation through grant PZENP2/173613. E.S. and G.D.T. acknowledge the ERC CoG project 614705 NOFEAR. M.V. acknowledges the European Research Council Starting Grant project 757290 BEFINE. C.C. and M.V. acknowledge professors C. Ancey and B. de Graffenried for their help with fluid viscosity measurements and scientific discussions. The authors acknowledge Editor Yves Bernabe, the Associate Editor, John Bedford, and an anonymous reviewer for their constructive comments that greatly improved the quality of our study. All the experimental raw data are available in Zenodo with the identifier: https:// doi.org/10.5281/zenodo.2669105. Correspondence and request for additional material should be addressed to chiara.cornelio@epfl.ch.

\section{References}

Abercrombie, R. E., \& Rice, J. R. (2005). Can observations of earthquake scaling constrain slip weakening? Geophysical Journal International, 162(2), 406-424. https://doi.org/10.1111/j.1365-246X.2005.02579.X

Acosta, M., Passelègue, F. X., Schubnel, A., \& Violay, M. (2018). Dynamic weakening during earthquakes controlled by fluid thermodynamics. Nature Communications, 9(1), 3074. https://doi.org/10.1038/s41467-018-05603-9

Bates, O. K. (1936). Binary mixtures of water and glycerol: Thermal conductivity of liquids. Industrial and Engineering Chemistry, 28(4), 494-498. https://doi.org/10.1021/ie50316a033

Beeler, N. M., Tullis, T. E., \& Goldsby, D. L. (2008). Constitutive relationships and physical basis of fault strength due to flash heating. Journal of Geophysical Research, 113(1), 1-12. https://doi.org/10.1029/2007JB004988

Bizzarri, A. (2012). The mechanics of lubricated faults: Insights from 3-D numerical models. Journal of Geophysical Research, 117(5), 1-23. https://doi.org/10.1029/2011JB008929

Brantut, N., \& Platt, J. D. (2017). Dynamic weakening and the depth dependence of earthquake faulting (pp. 171-194). Washington, DC: American Geophysical Union. https://doi.org/10.1002/9781119156895.ch9

Brantut, N., \& Viesca, R. C. (2017). The fracture energy of ruptures driven by flash heating. Geophysical Research Letters, 44(13), 6718-6725. https://doi.org/10.1002/2017GL074110

Brodsky, E. E., \& Kanamori, H. (2001). Elastohydrodynamic lubrication of faults. Journal of Geophysical Research, 106(B8), 16,357-16,374. https://doi.org/10.1029/2001JB000430

Byerlee, J. (1978). Friction of rocks. Pure and Applied Geophysics PAGEOPH, 116(4-5), 615-626. https://doi.org/10.1007/BF00876528

Cheng, N.-S. (2008). Formula for the viscosity of a glycerol-water mixture. Industrial \& Engineering Chemistry Research, 47(9), 3285-3288. https://doi.org/10.1021/ie071349z

Cocco, M., Spudich, P., \& Tinti, E. (2006). On the mechanical work absorbed on faults during earthquake ruptures. Agu Monograph: Earthquakes: Radiated Energy and the Physics of Faulting, 237-254. https://doi.org/10.1029/170GM24

Cornelio, C., Spagnuolo, E., Di Toro, G., Nielsen, S., \& Violay, M. (2019). Mechanical behaviour of fluid-lubricated faults. Nature Communications, 10(1), 1274. https://doi.org/10.1038/s41467-019-09293-9

Cornet, F. H. (2016). Seismic and aseismic motions generated by fluid injections. Geomechanics for Energy and the Environment, 5(January 2016), 42-54. https://doi.org/10.1016/j.gete.2015.12.003

Cornet, F. H., Helm, J., Poitrenaud, H., \& Etchecopar, A. (1997). Seismic and aseismic slips induced by large-scale fluid injections. Pure and Applied Geophysics, 150(3-4), 563-583. https://doi.org/10.1007/s000240050093

Di Toro, G., Niemeijer, A., Tripoli, A., Nielsen, S., Di Felice, F., Scarlato, P., et al. (2010). From field geology to earthquake simulation: A new state-of-the-art tool to investigate rock friction during the seismic cycle (SHIVA). Rendiconti Lincei, 21(1), 95-114. https://doi.org/ 10.1007/s12210-010-0097-X

Dieterich, J. H. (1979). Modeling of rock friction: 1. Experimental results and constitutive equations. Journal of Geophysical Research, 84(B5), 2161. https://doi.org/10.1029/JB084iB05p02161 
Economides, M. J., \& Boney, C. (2000). Reservoir stimulation in Petroleum Production. In Reservoir Stimulation (3rd ed., pp. 1-1,1-18). John Wiley \& Sons, University of Houston, USA

Ellsworth, W. L. (2013). Injection-induced earthquakes. Science, 341(6142), 1225942-1225942. https://doi.org/10.1126/science.1225942

Eppelbaum, L., Kutasov, I., \& Pilchin, A. (2014). Thermal properties of rocks and density of fluids. In Applied Geothermics (Chap. 2, pp. 99-150). Berlin, Heidelberg: Springer Berlin Heidelberg. https://doi.org/10.1007/978-3-642-34023-9

Giacomel, P., Spagnuolo, E., Nazzari, M., Marzoli, A., Passelègue, F. X., Youbi, N., \& Di Toro, G. (2018). Frictional instabilities and carbonation of basalts triggered by injection of pressurized $\mathrm{H}_{2} \mathrm{O}$ and $\mathrm{CO}_{2}$ rich fluids. Geophysical Research Letters, 45(12), 6032-6041. https://doi.org/10.1029/2018GL078082

Goertz-Allmann, B. P., Goertz, A., \& Wiemer, S. (2011). Stress drop variations of induced earthquakes at the Basel geothermal site. Geophysical Research Letters, 38(9). https://doi.org/10.1029/2011GL047498

Goldsby, D. L., \& Tullis, T. E. (2011). Flash heating leads to low frictional strength of crustal rocks at earthquake slip rates. Science, 334(6053), 216-218. https://doi.org/10.1126/science.1207902

Gomberg, J., Blanpied, M. L., \& Beeler, N. M. (1997). Transient triggering of near and distant earthquakes. Bulletin of the Seismological Society of America, 87(2), 294-309. Retrieved from https://pubs.geoscienceworld.org/ssa/bssa/article-abstract/87/2/294/102731

Goranson, R. W. (1942). Heat capacity: Heat of fusion. In F. B. Chairman, J. F. Schairer, \& H. C. Spicer (Eds.), Handbook of Physical Constants (pp. 223-240). New York: Geological Society of America. https://doi.org/10.1130/SPE36-p223

Gu, J.-C., Rice, J. R., Ruina, A. L., \& Tse, S. T. (1984). Slip motion and stability of a single degree of freedom elastic system with rate and state dependent friction. Journal of the Mechanics and Physics of Solids, 32(3), 167-196. https://doi.org/10.1016/0022-5096(84) 90007-3

Guatteri, M., \& Spudich, P. (2000). What can strong-motion data tell us about slip-weakening fault-friction laws? Bulletin of the Seismological Society of America, 90(1), 98-116. https://doi.org/10.1785/0119990053

Guglielmi, Y., Cappa, F., Avouac, J.-P., Henry, P., \& Elsworth, D. (2015). Seismicity triggered by fluid injection-induced aseismic slip. Science, 348(6240), 1224-1226. https://doi.org/10.1126/science.aab0476

Harris, R. A. (1998). Introduction to Special Section: Stress triggers, stress shadows, and implications for seismic hazard. Journal of Geophysical Research, 103(B10), 24,347-24,358. https://doi.org/10.1029/98JB01576

Ikari, M. J., Saffer, D. M., \& Marone, C. (2009). Frictional and hydrologic properties of clay-rich fault gouge. Journal of Geophysical Research, 114(March), 1-18. https://doi.org/10.1029/2008JB006089

Jost, M. L., Büßelberg, T., Jost, Ö., \& Harjes, H. P. (1998). Source parameters of injection-induced microearthquakes at $9 \mathrm{~km}$ depth at the KTB deep drilling site, Germany. Bulletin of the Seismological Society of America, 88(3), 815-832. https://doi.org/10.1666/0022-3360 (2000) $074<0767:$ PAEFTN $>2.0 . \mathrm{CO} ; 2$

Kanamori, H., \& Rivera, L. (2006). Energy partitioning during an earthquake. In Earthquakes: Radiated Energy and the Physics of Faulting (pp. 3-13). Washington, DC: American Geophysical Union. https://doi.org/10.1029/170GM03

Kilb, D., Gomberg, J., \& Bodin, P. (2000). Triggering of earthquake aftershocks by dynamic stresses. Nature, 408(6812), 570-574. https://doi. org/10.1038/35046046

Majer, E. L., Baria, R., Stark, M., Oates, S., Bommer, J., Smith, B., \& Asanuma, H. (2007). Induced seismicity associated with Enhanced Geothermal Systems. Geothermics, 36(3), 185-222. https://doi.org/10.1016/j.geothermics.2007.03.003

Malagnini, L., Mayeda, K., Nielsen, S., Yoo, S.-H., Munafó, I., Rawles, C., \& Boschi, E. (2014). Scaling transition in earthquake sources: A possible link between seismic and laboratory measurements. Pure and Applied Geophysics, 171(10), 2685-2707. https://doi.org/10.1007/ s00024-013-0749-8

Miller, S. A., Collettini, C., Chiaraluce, L., Cocco, M., Barchi, M., \& Kaus, B. J. P. (2004). Aftershocks driven by a high-pressure $\mathrm{CO}_{2}$ source at depth. Nature, 427(6976), 724-727. https://doi.org/10.1038/nature02251

Nasseri, M. H. B., Schubnel, A., Benson, P. M., \& Young, R. P. (2009). Common evolution of mechanical and transport properties in thermally cracked Westerly granite at elevated hydrostatic pressure. Pure and Applied Geophysics, 166(5-7), 927-948. https://doi.org/ 10.1007/s00024-009-0485-2

Nielsen, S., Spagnuolo, E., Smith, S. A. F., Violay, M., Di Toro, G., \& Bistacchi, A. (2016). Scaling in natural and laboratory earthquakes. Geophysical Research Letters, 43(4), 1504-1510. https://doi.org/10.1002/2015GL067490

Nielsen, S., Spagnuolo, E., \& Violay, M. (2012). Composite SAmple MOunt Assembly (SAMOA): The Ultimate Sample Preparation for Rotary Shear Experiments. Rome: Rapporti Tecnici, INGV.

Nielsen, S., Spagnuolo, E., Violay, M., Smith, S., Di Toro, G., \& Bistacchi, A. (2016). G: Fracture energy, friction and dissipation in earthquakes. Journal of Seismology, 20(4), 1187-1205. https://doi.org/10.1007/s10950-016-9560-1

Niemeijer, A., Di Toro, G., Nielsen, S., \& Di Felice, F. (2011). Frictional melting of gabbro under extreme experimental conditions of normal stress, acceleration, and sliding velocity. Journal of Geophysical Research, 116(B7), B07404. https://doi.org/10.1029/2010JB008181

Niemeijer, A. R., \& Collettini, C. (2014). Frictional properties of a low-angle normal fault under in situ conditions: Thermally-activated velocity weakening. Pure and Applied Geophysics, 171(10), 2641-2664. https://doi.org/10.1007/s00024-013-0759-6

Ohnaka, M. (2003). A constitutive scaling law and a unified comprehension for frictional slip failure, shear fracture of intact rock, and earthquake rupture. Journal of Geophysical Research, 108(B2), 1-21. https://doi.org/10.1029/2000JB000123

Palmer, A. C., \& Rice, J. R. (1973). The growth of slip surfaces in the progressive failure of over-consolidated clay. Proceedings of the Royal Society A: Mathematical, Physical and Engineering Sciences, 332(1591), 527-548. https://doi.org/10.1098/rspa.1973.0040

Passelègue, F. X., Brantut, N., \& Mitchell, T. M. (2018). Fault reactivation by fluid injection: Controls from stress state and injection rate Geophysical Research Letters, 45, 2018GL080470. https://doi.org/10.1029/2018GL080470

Passelègue, F. X., Goldsby, D. L., \& Fabbri, O. (2014). The influence of ambient fault temperature on flash-heating phenomena. Geophysical Research Letters, 41(3), 828-835. https://doi.org/10.1002/2013GL058374

Passelègue, F. X., Latour, S., Schubnel, A., Nielsen, S., Bhat, H. S., \& Madariaga, R. (2017). Influence of fault strength on precurosy processes during laboratory earthquakes. In Geophysical Monograph Series (Vol. 227, pp. 229-242). Washington, DC: American Geophysical Union.

Passelègue, F. X., Spagnuolo, E., Violay, M., Nielsen, S., Di Toro, G., \& Schubnel, A. (2016). Frictional evolution, acoustic emissions activity, and off-fault damage in simulated faults sheared at seismic slip rates. Journal of Geophysical Research: Solid Earth, 121, $7490-7513$. https://doi.org/10.1002/2016JB012988

Rice, J. R. (2006). Heating and weakening of faults during earthquake slip. Journal of Geophysical Research, 111(B5). https://doi.org/10.1029/2005JB004006

Rice, J. R., \& Ruina, A. L. (1983). Stability of steady frictional slipping. Journal of Applied Mechanics, 50(2), 343. https://doi.org/10.1115/ 1.3167042 
Scholz, C. H. (2019). Rock friction. In The Mechanics of Earthquakes and Faulting (pp. 43-96). New York: Cambridge University Press. https://doi.org/10.1017/9781316681473.005

Scuderi, M. M., \& Collettini, C. (2016). The role of fluid pressure in induced vs. triggered seismicity: Insights from rock deformation experiments on carbonates. Scientific Reports, 6(1), 24852. https://doi.org/10.1038/srep24852

Scuderi, M. M., Collettini, C., \& Marone, C. (2017). Frictional stability and earthquake triggering during fluid pressure stimulation of an experimental fault. Earth and Planetary Science Letters, 477, 84-96. https://doi.org/10.1016/j.epsl.2017.08.009

Shipton, Z. K., Evans, J. P., Abercrombie, R. E., \& Brodsky, E. E. (2006). The missing sinks: Slip localization in faults, damage zones, and the seismic energy budget. In Earthquakes: Radiated Energy and the Physics of Faulting (Vol. 170, pp. 217-222). Washington, DC: American Geophysical Union. https://doi.org/10.1029/170GM22

Sibson, R. H. (1973). Interactions between temperature and pore-fluid pressure during earthquake faulting and a mechanism for partial or total stress relief. Nature Physical Science, 243(126), 66-68. https://doi.org/10.1038/physci243066a0

Sibson, R. H. (1992). Fault-valve behavior and the hydrostatic-lithostatic fluid pressure interface. Earth Science Reviews, 32(1-2), 141-144. https://doi.org/10.1016/0012-8252(92)90019-P

Spagnuolo, E. (2006). Evoluzione della trazione dinamica sulla faglia durante I forti terremoti. Rome: Univ. degli Studi di Roma "La Sapienza”.

Spagnuolo, E., Nielsen, S., Violay, M., \& Di Toro, G. (2016). An empirically based steady state friction law and implications for fault stability. Geophysical Research Letters, 43(7), 3263-3271. https://doi.org/10.1002/2016GL067881

Tinti, E., Spudich, P., \& Cocco, M. (2005). Earthquake fracture energy inferred from kinematic rupture models on extended faults. Journal of Geophysical Research, 110(12), 1-25. https://doi.org/10.1029/2005JB003644

Tsutsumi, A., \& Shimamoto, T. (1997). High-velocity frictional properties of gabbro. Geophysical Research Letters, 24(6), 699-702. https:// doi.org/10.1029/97GL00503

Venkataraman, A., \& Kanamori, H. (2004). Observational constraints on the fracture energy of subduction zone earthquakes. Journal of Geophysical Research, 109. https://doi.org/10.1029/2003JB002549

Viesca, R. C., \& Garagash, D. I. (2015). Ubiquitous weakening of faults due to thermal pressurization. Nature Geoscience, 8(11), 875-879. https://doi.org/10.1038/ngeo2554

Violay, M., Di Toro, G., Nielsen, S., Spagnuolo, E., \& Burg, J. P. (2015). Thermo-mechanical pressurization of experimental faults in cohesive rocks during seismic slip. Earth and Planetary Science Letters, 429, 1-10. https://doi.org/10.1016/j.epsl.2015.07.054

Violay, M., Nielsen, S., Gibert, B., Spagnuolo, E., Cavallo, A., Azais, P., et al. (2014). Effect of water on the frictional behavior of cohesive rocks during earthquakes. Geology, 42(1), 27-30. https://doi.org/10.1130/G34916.1

Violay, M., Nielsen, S., Spagnuolo, E., Cinti, D., Di Toro, G., \& Di Stefano, G. (2013). Pore fluid in experimental calcite-bearing faults: Abrupt weakening and geochemical signature of co-seismic processes. Earth and Planetary Science Letters, 361, 74-84. https://doi.org/ 10.1016/j.epsl.2012.11.021

Wu, Q., Chapman, M., \& Chen, X. (2018). Stress-drop variations of induced earthquakes in Oklahoma. Bulletin of the Seismological Society of America, 108(3A), 1107-1123. https://doi.org/10.1785/0120170335

Ye, Z., \& Ghassemi, A. (2018). Injection-induced shear slip and permeability enhancement in granite fractures. Journal of Geophysical Research: Solid Earth, 123(10), 9009-9032. https://doi.org/10.1029/2018JB016045

Zoback, M. D., \& Harjes, H.-P. (1997). Injection-induced earthquakes and crustal stress at $9 \mathrm{~km}$ depth at the KTB deep drilling site, Germany. Journal of Geophysical Research, 102(B8), 18,477-18,491. https://doi.org/10.1029/96JB02814 